\title{
Misalignment and Range Adaptive Wireless Charging System with Constant Current/Constant Voltage Output Based on Coupling Coefficient Estimation
}

\author{
Wangqiang Niu ${ }^{1}$, Jiaojiao Liu ${ }^{1}$, Zaixing $\mathrm{Chen}^{2}$, Wei Gu \\ ${ }^{1}$ Key Laboratory of Transport Industry of Marine Technology and Control Engineering, Shanghai \\ Maritime University, Shanghai 201306, China. \\ ${ }^{2}$ Shanghai Zhenhua Heavy Industries Co., Ltd, Shanghai 200125, China. \\ Received: July 18, 2020. Revised: March 13, 2021. Accepted: April 6, 2021. Published: April 8, 2021.
}

\begin{abstract}
Compared with the traditional plug-in charging system, wireless power transfer (WPT) system has the characteristics of electrical and mechanical isolation. A wireless system is proposed suitable for battery charging under misalignment or range variation, and the constant current (CC) and constant voltage $(\mathrm{CV})$ charging are realized by the estimation of coupling coefficient. Firstly, two different operating frequencies based on SS basic compensation structure are designed to realize CC output and CV output respectively. After circuit analysis, CC and $C V$ output cannot be achieved when the position of the secondary coil changes. To solve this issue, when the coil is under misalignment or range variations, the required system parameters are measured, and the coupling coefficient in the charging process is estimated by using the transconductance amplitude equation. Then the corresponding input voltage or working frequency is calculated and fine-tuned. Therefore, the CC and CV charge of the battery can be realized under misalignment or range variation. Finally, experimental results are presented to verify the feasibility and correctness of this method.
\end{abstract}

Keywords-Systems Theory, Applied Systems Theory, Battery charging, Constant current output (CC), Constant voltage output (CV), Coupling coefficient estimation, Wireless power transfer (WPT).

\section{INTRODUCTION}

$\mathrm{W}$ ith the development of power electronics and electromagnetic field theory, electric energy can be transmitted in a non-contact way. Wireless power transfer (WPT) uses induction coupling [1], magnetic resonance coupling [2], laser and microwave to transmit energy [3], which is a safe, reliable and convenient way to transmit power [4-6]. Compared with the traditional wired power transfer, WPT has the characteristics of electrical and mechanical isolation, avoiding the appearance of electric spark, safety and reliability, flexibility and convenience. Therefore, this method can be applied in a variety of extreme environments. At present, typical application fields include electronic products, automated guided vehicle (AGV), biomedical equipment, underwater and mine equipment, etc. [7-10]. With the aggravation of air pollution and energy consumption in recent years, electric vehicles with their clean and efficient characteristics are gradually replacing the traditional fuel vehicles. The application of radio energy transfer technology to electric vehicle power supply has also become a hot topic [11].

Battery is an important part of electric vehicles and the key to the normal operation of electric vehicles [12]. There are three battery charging methods: constant current (CC) charging method, two-stage charging method, constant voltage (CV) charging method. In the late stage of CC charging method, charging current is mainly used to electrolyze water and produce gas, which makes the gas exhaled too much. In the initial stage of CV charging, the current is too large, which has a great impact on the battery life, and it is easy to make the battery plate bend, resulting in battery scrap. The mixed constant current/constant voltage method overcomes the deficiency of the first two methods, but it can't eliminate the polarization phenomenon when the battery is charged, which will affect the charging effect. Therefore, the two-stage charging method, which combines $\mathrm{CC}$ and $\mathrm{CV}$, is often used. For a start, it is in the $\mathrm{CC}$ mode. As the battery voltage rises to a certain level, the charging process switches to the $\mathrm{CV}$ mode $[13,14]$. The battery has a wide range of voltage variation during the charging process, in order to extend the service life of the battery, the charging system needs to accurately meet the required charging current and voltage. The output state of the wireless charging system is affected by a variety of parameters and working conditions, so it is necessary to ensure that the output load characteristic curve conforms to the battery charging curve and has certain load adaptability [11].

In general, wireless charging methods to realize $\mathrm{CC}$ and $\mathrm{CV}$ output of batteries can be divided into two types: variable topology-based method and variable working frequency-based method. The method of variable topology is to adopt compound 
topology structure, one topology for $\mathrm{CC}$, another for $\mathrm{CV}$, and the operating frequency keeps unchanged. In 2015, Qu et al. proposed a hybrid charging topology based on series-series (SS) and parallel-series (PS) compensation or series-parallel (SP) and parallel-parallel (PP) compensation [15, 16]. In 2017, Huang et al. designed a WPT system for battery charging. LCL-LCL topology is used to realize CC output and LCL-S topology is used to realize CV output [17]. In 2018, Li et al. designed the hybrid topology of three-coil WPT system to realize $\mathrm{CC}$ and $\mathrm{CV}$ output. The three-coil WPT system has better performance than the two-coil WPT system when the transmission distance is increased [18]. However, the variable topology method increases the number and complexity of components, and the system may be in a state of detuning when the coil is misalignment, thus reducing the transfer efficiency.

The method of variable operating frequency is to realize the charging characteristic of battery with $\mathrm{CC}$ and $\mathrm{CV}$ in a single topology, but two operating frequencies are needed in the charging process. In 2014, Huang proposed that the SS topology could achieve CC and CV output at two different frequencies, but the coil misalignment issue was not considered [19]. In 2018, Tran et al. added two intermediate coils with resonant capacitors to improve the power transfer efficiency. The resonant tank is designed as two current and voltage sources with different frequencies to realize $\mathrm{CC}$ and $\mathrm{CV}$ output respectively [20]. In October 2018, $\mathrm{Vu}$ et al. proposed the double-sided LCC compensation tank which can achieve both $\mathrm{CC}$ and $\mathrm{CV}$ mode charge under zero phase angle (ZPA) condition at two different resonant frequencies [21]. In March 2019, Qu et al. proposed a double-sided LC compensation circuit in order to achieve load-independent $\mathrm{CC}$ output and zero reactive power input [22]. They gave the efficiency of their WPT systems at fixed frequency under various misalignment, but no solution is given to tackle the misalignment issue.

Therefore, it is necessary to solve the problem that $\mathrm{CC}$ and $\mathrm{CV}$ output can be achieved under coil dislocation. In this kind of system, information of system parameters, especially the coupling coefficient, is needed. Consequently, coupling coefficient estimation is the key factor to realize the wireless battery charging. A dynamic coupling coefficient estimation method requiring secondary side parameters is proposed in [23] and [24] to achieve the maximum transfer efficiency of the wireless system. In [25], the coupling coefficient is estimated by using the relationship between the coupling coefficient and the duty cycle of Buck-Boost circuits. In [26], the coupling coefficients are identified by the input impedance equation, and only one solution is found, avoiding the two-solution method in [25]. In this paper, it is proposed that the required $\mathrm{CC}$ and $\mathrm{CV}$ output can still be achieved by coupling $k$ estimation under the condition of the misalignment or range variation. It also helps to protect the battery and improve the life of the battery. In addition, closed-loop control is used to realize the stable and accurate control of charging current and charging voltage. The $\mathrm{SS}$ topology for $\mathrm{CC} / \mathrm{CV}$ charging under a closed loop control has some commercial value. Compared with the method of variable topology-based, our method reduces the number and complexity of components. Compared with the method of variable working frequency-based, we can realize the $\mathrm{CC}$ and $\mathrm{CV}$ charging of the battery through closed-loop control when the position of the secondary coil changes.

The method of variable operating frequency was adopted in this study. A wireless charging system suitable for battery charging under misalignment or range variation is designed, and $\mathrm{CC}$ and $\mathrm{CV}$ charging are realized by the estimation of coupling coefficient. This system adopts a SS basic compensation structure to realize $\mathrm{CC}$ and $\mathrm{CV}$ charging under different equivalent loads. It is designed as two current and voltage sources with different frequencies to realize constant current output and constant voltage output respectively. After analysis, the working frequency is fixed in $\mathrm{CC}$ mode and cannot be changed. The output current can reach the desired current by adjusting the input voltage. In $\mathrm{CV}$ mode, the coupling coefficient is related to the operating frequency. It is necessary to first estimate the coupling coefficient. Then calculate the working frequency, and further fine-tune the working frequency to make the output voltage CV charge. When the coil is under misalignment or range variations, the required system parameters are measured, and the coupling coefficient in the charging process is estimated by using the transconductance amplitude equation. Then the corresponding input voltage or working frequency is calculated and fine-tuned. Therefore, the $\mathrm{CC}$ and $\mathrm{CV}$ charge of the battery can be realized under misalignment and range variation.

\section{Circuit Structure AND Working PrinciPle}

\section{A. Circuit Analysis and Equivalent Circuit Model Based} on SS Compensation Topology

The core component of WPT system is a loose-coupling transformer. Due to the existence of air gap, a loose-coupling transformer has a high leakage inductance [6], so it needs to add compensating capacitor to compensate reactive power. At present, the most commonly used compensation methods show four structures: SS, SP, PS, PP [16] as shown in Fig. 1. By analyzing the input and output characteristics of four basic WPT compensation structures, the topological structure and working conditions that can realize $\mathrm{CC}$ or $\mathrm{CV}$ output are found. Taking SS topology as an example and applying Kirchhoff's voltage law to the circuit, the voltage equation (1) can be obtained:

$$
\left\{\begin{array}{l}
\mathcal{L}_{i n}^{\&}=\left(j \omega L_{p}+\frac{1}{j \omega C_{p}}\right) I_{1}^{\&}-j \omega M I_{2}^{\&} \\
0=-j \omega M I_{1}^{\&}+\left(j \omega L_{s}+\frac{1}{j \omega C_{s}}+R_{L, e q}\right) I_{2}^{\&}
\end{array}\right.
$$

where $L_{P}$ and $L_{S}$ are the self-inductance of the primary and secondary coils respectively, $C_{P}$ and $C_{S}$ are the compensation capacitors of the primary and secondary coils respectively, $M$ is the mutual inductance between two coils, $R_{L}$ is the load and $\omega$ is the operating frequency. Here, the coil resistance is neglected since the most of the voltage is applied to the coil inductance. (1) can be simplified to (2). 


$$
\left\{\begin{array}{l}
\frac{U_{\text {in }}^{\&}}{j \omega L_{p}}=\left(1-\frac{\omega_{0}^{2}}{\omega^{2}}\right) H_{1}^{\&}+k \sqrt{\frac{L_{s}}{L_{p}}} I_{2}^{\&} \\
0=k \sqrt{\frac{L_{p}}{L_{s}}} I_{1}^{\&}+\left(1-\frac{\omega_{0}^{2}}{\omega^{2}}+\frac{R_{L, e q}}{j \omega L_{s}}\right) H_{2}^{\&}
\end{array}\right.
$$

where $k$ is the coupling coefficient of the two coils, equal to $M / \sqrt{L_{p} L_{s}}$ and $\omega_{0}$ is the resonant frequency of the two coils, equal to $1 / \sqrt{L_{p} C_{p}}$.

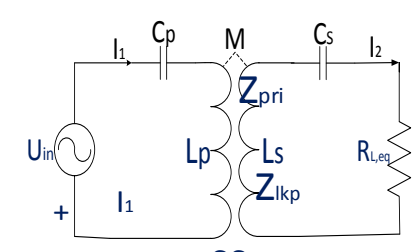

\section{SS}

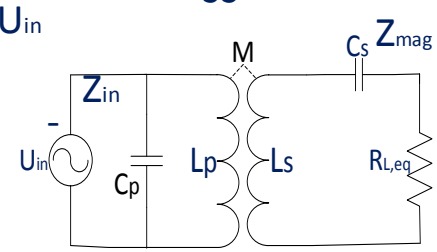

PS

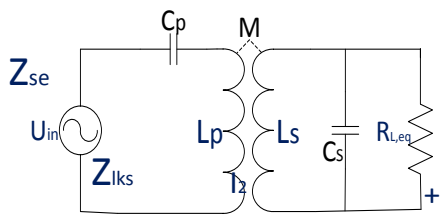

$\mathrm{SP}$

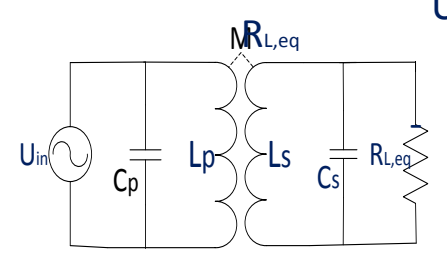

PP
Fig. 1. Four basic compensation topologies of WPT systems.

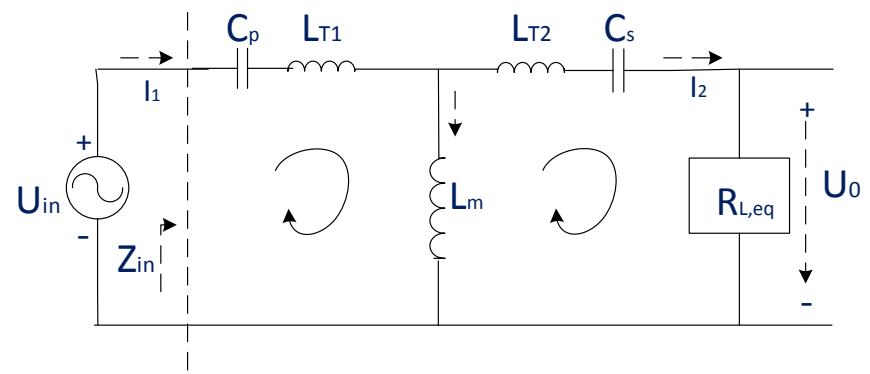

Fig. 2. Equivalent circuit model of T-type based on SS compensation topology.

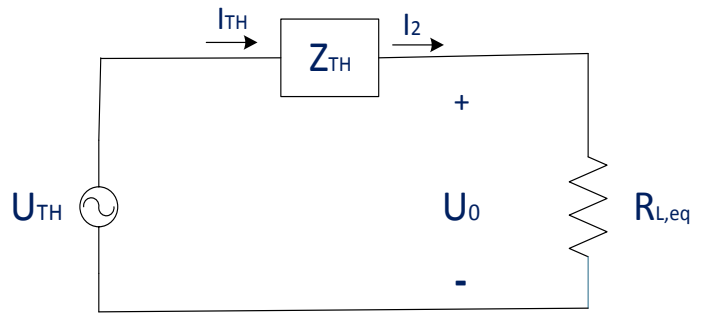

Fig. 3. Equivalent circuit of WPT system.

There are two equivalent circuit models of loosely-coupled transformers: M-type and T-type. T-type equivalent circuit model is used in this paper. Therefore, the equivalent circuit model of the T-type transformer based on the SS topology as shown in Fig. 2 [27], and two closed-loop voltage equations can be obtained as $Z_{\text {pri }}$

$Z_{\text {se }}$

$$
+\left\{\begin{array}{c}
U_{\text {in }}^{\&}=I_{1}^{\&} \cdot\left(\frac{1}{Z_{\text {in }} C_{\mathrm{k}} C_{p}}+j \omega L_{T 1}+j \omega L_{m}\right)-I_{2}^{\&} \cdot j \omega L_{m} \\
\mathrm{Z}_{\mathrm{lks}}
\end{array}\right.
$$$$
Z_{\text {mag }}
$$$$
\mathrm{R}_{\mathrm{L}, \mathrm{eq}}
$$

where $L_{m}$ is the equivalent excitation reactance, $L_{m}=M . L_{T 1}$ and $L_{T 2}$ indicate the leakage inductance of the primary side and the secondary side after reduction of a transformer, respectively, $L_{T 1}=L_{p}-M$, and $L_{T 2}=L_{s}-M$.

For further analysis, let

$$
\left\{\begin{array}{l}
Z_{1}=\frac{1}{j \omega C_{p}}+j \omega L_{T 1}+j \omega L_{m} \\
Z_{2}=\frac{1}{j \omega C_{s}}+j \omega L_{T 2}+j \omega L_{m} \\
Z_{3}=j \omega L_{m}
\end{array}\right.
$$

By substituting (4) into (3), (3) can be rewritten as

$$
\mathrm{L}_{\mathrm{I} 1} \quad\left\{\begin{array}{l}
\mathcal{U}_{i n}^{\&}=\mathrm{Z}_{1} \&-\mathrm{Z}_{3} \& \\
0=\mathrm{Z}_{3} \&-\left(\mathrm{Z}_{2}+\mathrm{R}_{\mathrm{L}, \mathrm{eq}}\right)_{2}^{\&}
\end{array}\right.
$$

Comparison with (2), and let $L_{p}$ equal $L_{s} . Z_{1}, Z_{2}$ and $Z_{3}$ can also be derived as

$L_{12}$

$$
\left\{\begin{array}{l}
Z_{1}=Z_{2}=j \omega L_{p} \times\left(1-\frac{\omega_{0}^{2}}{\omega^{2}}\right) \\
Z_{3}=j w \sqrt{L_{p} L_{s}} \times k
\end{array}\right.
$$

\section{B. CC and CV Mode Operating Frequency Analysis}

The equivalent circuit model of the T-type transformer based on the SS topology shown in Fig. 2 can be further simplified by using Thevenin theorem as shown in Fig. 3. The equations of Thevenin equivalent circuit can be derived as

$$
\begin{gathered}
U_{T H}^{\&}=U_{\text {in }}^{\&} \frac{Z_{3}}{Z_{1}} \\
Z_{T H}=\frac{Z_{1} Z_{2}-Z_{3}^{2}}{Z_{1}}=\frac{Z_{1}^{2}-Z_{3}^{2}}{Z_{1}} \\
\&_{T H}^{\&}=\frac{U_{T H}^{\&}}{Z_{T H}+R_{L, e q}}=\frac{U_{i n}^{\&} Z_{3}}{Z_{1}^{2}-Z_{3}^{2}+Z_{1} R_{L, e q}} \\
U_{0}^{\&}=\frac{U_{T H}^{\&} R_{L, e q}}{Z_{T H}+R_{L, e q}}=U_{i n}^{\&} \frac{Z_{3} R_{L, e q}}{Z_{1}^{2}-Z_{3}^{2}+Z_{1} R_{L, e q}}
\end{gathered}
$$

$U_{T H}$ and $Z_{T H}$ represent the Thevenin voltage and Thevenin impedance of the circuit, respectively. $I_{T H}$ and $U_{0}$ are output current and output voltage [20].

In order to satisfy the CC output, it can be seen from (9) that when $Z_{1}$ is equal to $0, I_{2}$ is a constant no matter what value $R_{L, e q}$ . $t_{2}^{\&}$ is now

$$
f_{2}^{\&}=I_{T H}^{\&}=\frac{U_{i n}^{\&}}{Z_{3}}=\frac{U_{i n}^{\&}}{j \omega \sqrt{L_{p} L_{s}} \times k}
$$

At this point the operating frequency is at the resonant frequency

$$
\omega_{c}=\omega_{0}=\frac{1}{\sqrt{L_{p} C_{p}}}
$$

\footnotetext{
$Z_{\text {in }}$
} 
Substitute (12) into (11) to obtain the output current:

$$
H_{2}^{\&}=\frac{U_{i n}^{\&} \sqrt{C_{p}}}{j \sqrt{L_{s}} \times k}
$$

It can be seen from (13) that the output current in the $\mathrm{CC}$ mode is related to the coupling $k$. Figure 4 shows the curve of output current relative to frequency under variable load. It can be seen that the $\mathrm{CC}$ mode charging of $1.05 \mathrm{~A}$ can be realized at $43.2 \mathrm{kHz}$.

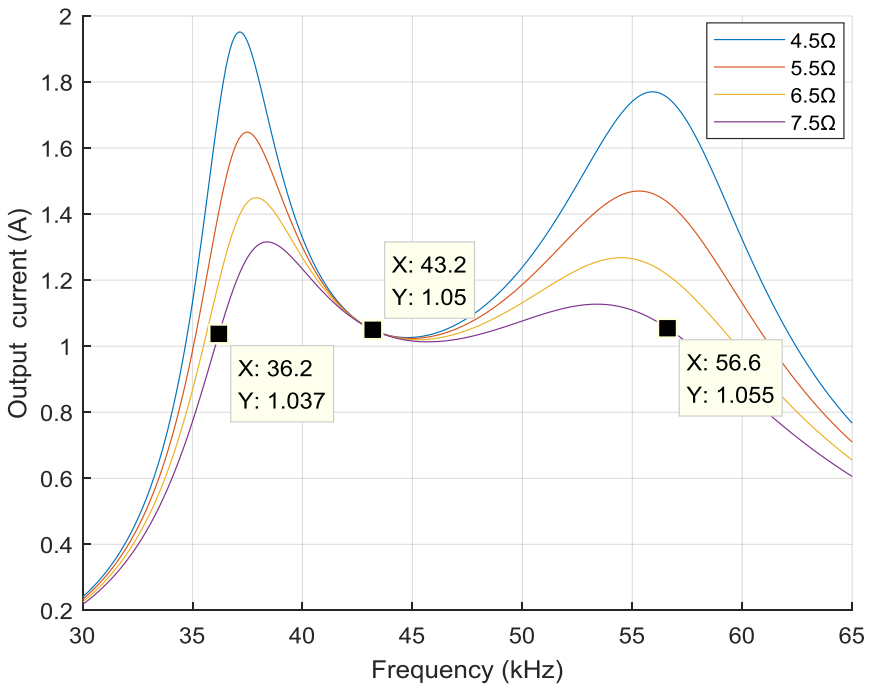

Fig. 4. Output current curves of the proposed system at different loads in CC mode operation.

In addition, since $Z_{1}=Z_{2}=0$, the input impedance $Z_{\text {in }}$ of the WPT system becomes a real number as shown in (14).

$$
\begin{aligned}
& Z_{i n}=\left(\frac{1}{j \omega C_{p}}+j \omega L_{T 1}\right)+ \\
& \frac{\left(\frac{1}{j \omega C_{s}}+j \omega L_{T 2}+R_{L, e q}\right) \cdot j \omega L_{m}}{j \omega L_{m}+\left(\frac{1}{j \omega C_{s}}+j \omega L_{T 2}+R_{L, e q}\right)} \\
& =Z_{1}-Z_{3}+\frac{\left(Z_{2}-Z_{3}+R_{L, e q}\right) Z_{3}}{Z_{2}+R_{L, e q}} \\
& =\frac{-Z_{3}^{2}}{R_{L, e q}}=\frac{k^{2} L_{s}}{R_{L, e q} C_{p}}
\end{aligned}
$$

Hence, the ZPA condition can be obtained in the CC mode charge.

In order to satisfy the $\mathrm{CV}$ output, it can be seen from (10) that when $Z_{1}^{2}-Z_{3}^{2}=0$ holds, $U_{0}$ is a constant regardless of value $R_{L, e q}$. The system voltage output and operating frequency are shown in (15) and (16), respectively.

$$
\begin{aligned}
& \mathcal{U}_{0}^{\&}=U_{\text {in }}^{\&} \frac{Z_{3}}{Z_{1}}=\frac{U_{i n}^{\&} \sqrt{L_{s}}}{\left(1-\frac{\omega_{0}^{2}}{\omega^{2}}\right) \sqrt{L_{p}}} \times k \\
& \omega_{v 1}=\frac{\omega_{0}}{\sqrt{1-k}} ; \omega_{v 2}=\frac{\omega_{0}}{\sqrt{1+k}}
\end{aligned}
$$

where $\omega_{v 1}$ is the above resonance frequency, $\omega_{v 2}$ is the below resonance frequency, and $\omega_{v 2}<\omega_{c}<\omega_{v 1}$ holds. To verify the above analysis, Fig. 5 shows the gain curve of output voltage relative to frequency under variable load. It can be seen that $\mathrm{CV}$ charging can be realized at $36.2 \mathrm{kHz}$ or $56.6 \mathrm{kHz}$.

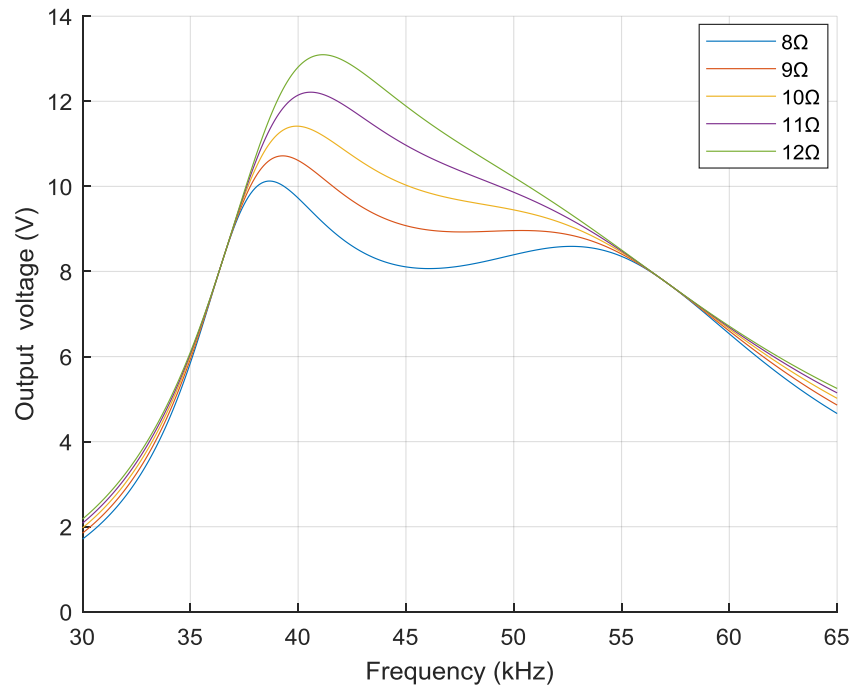

Fig. 5. Output voltage curves of the proposed system at different loads in CV mode operation.

Substitute the above resonance frequency $\omega_{v 1}$ into (15) to obtain the output voltage

$$
U_{0}^{\&}=\frac{\mathcal{U}_{i n}^{\&} \sqrt{L_{s}}}{\left(1-\frac{\omega_{0}^{2}}{\left(\frac{\omega_{0}}{\sqrt{1-k}}\right)^{2}}\right) \sqrt{L_{p}}} \times k=\mathcal{G}_{\text {in }}^{\&}
$$

Substitute the below resonance frequency $\omega_{v 2}$ into (15) to obtain the output voltage

$$
\mathcal{U}_{0}^{\&}=\frac{\mathcal{L}_{i n}^{\&} \sqrt{L_{s}}}{\left(1-\frac{\omega_{0}^{2}}{\left(\frac{\omega_{0}}{\sqrt{1+k}}\right)^{2}}\right) \sqrt{L_{p}}} \times k=-\mathcal{U}_{i n}^{\&}
$$

where $L_{p}$ is equal to $L_{s}$. In CV mode, the output voltage and the input voltage are in phase at the above resonance frequency, while they are out of phase at the lower resonance frequency $\omega_{v 2}$.

At the above resonance frequency $\omega_{v 1}$, that's $Z_{3}=Z_{1}$, the input impedance and its phase are

$$
\begin{gathered}
Z_{\text {in }}=\frac{Z_{1} R_{L, e q}}{Z_{1}+R_{L, e q}}=\frac{Z_{1} R_{L, e q}\left(R_{L, e q}-Z_{1}\right)}{R_{L, e q}^{2}+\left|Z_{1}\right|^{2}} \\
=\frac{\omega_{0} L_{p} k R_{L, e q}\left(\omega_{0} L_{p} k+j \sqrt{1-k} R_{L, e q}\right)}{\sqrt{1-k} R_{L, e q}^{2}+\left(\omega_{0} L_{p} k\right)^{2}} \\
\arg Z_{i n}=\arctan \left(\frac{\sqrt{1-k} R_{L, e q}}{k \omega_{0} L_{p}}\right)
\end{gathered}
$$

It can be seen from (19) that the ZPA condition cannot be obtained in $\mathrm{CV}$ mode charge at the above resonance frequency $\omega_{v 1}$. According to (20), the input impedance is inductive, which is beneficial to realize zero-voltage switching (ZVS). 


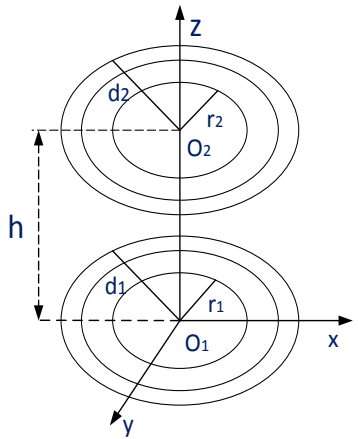

(a)

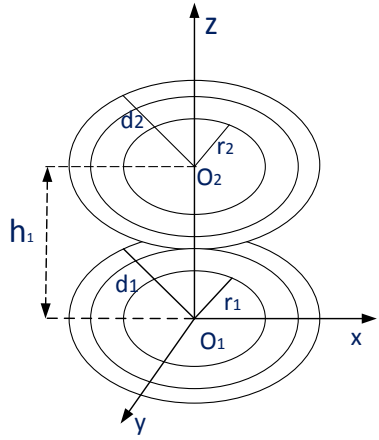

(b)

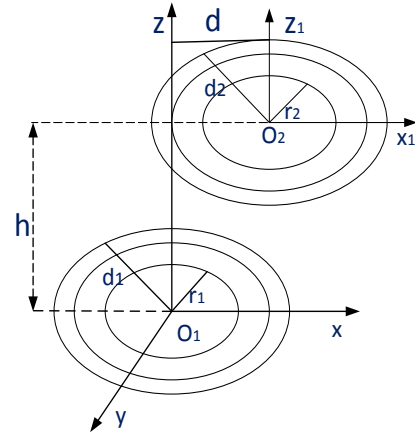

(c)

Fig. 6. Coil configurations with various spatial scales. (a) Ideal alignment. (b) Range shortened. (c) Lateral misalignment.

At the below resonance frequency $\omega_{v 2}$, that's $Z_{3}=-Z_{1}$, the input impedance and its phase are

$$
\begin{gathered}
Z_{\text {in }}=\frac{Z_{1} R_{L, e q}}{Z_{1}+R_{L, e q}}=\frac{\omega_{0} L_{p} k R_{L, e q}\left(-\omega_{0} L_{p} k+j \sqrt{1+k} R_{L, e q}\right)}{\sqrt{1+k} R_{L, e q}^{2}+\left(\omega_{0} L_{p} k\right)^{2}} \\
\arg Z_{\text {in }}=\arctan \left(-\frac{\sqrt{1+k} R_{L, e q}}{k \omega_{0} L_{p}}\right)
\end{gathered}
$$

The ZPA condition cannot be obtained in the CV mode charge from (21) at the lower resonance frequency $\omega_{v 2}$. From (22), the input impedance is capacitive, which is beneficial to realize zero-current switching (ZCS).

Now the system transfer efficiency is calculated.

The load power of the system is

$$
P_{\text {load }}=\frac{U_{0}^{2}}{R_{L, e q}}
$$

where $U_{0}$ is the output voltage of the system, and $R_{L, e q}$ is the load resistance.

The input power of the system is defined by

$$
P_{i n}=\mathrm{U}_{1} I_{1} \cos \theta
$$

where $U_{1}$ refers to the voltage across the transmitting coil and the transmitting capacitor, $I_{1}$ is the primary side current, and $\theta$ is the phase difference between $\mathrm{U}_{1}$ and $I_{1}$.

The measured transfer efficiency of the system is deduced as

$$
\eta=\frac{P_{\text {load }}}{P_{\text {in }}}=\frac{U_{0}^{2} / R_{L, e q}}{\mathrm{U}_{1} I_{1} \cos \theta}
$$

Similarly, the operating frequencies of the other three topologies satisfying the $\mathrm{CC}$ or $\mathrm{CV}$ output can be obtained. PS and PP topologies need relatively large working frequency to achieve CC output, while SP topologies cannot achieve load-independent CV output. After comparison, SS topology is selected in this study to realize CC and CV output.

\section{Control Strategy Based on Coupling Coefficient}

\section{Estimation}

When a wireless charger is used, different situations may occur between the two coil centers as shown in Figure 6[28]. Under the ideal alignment shown in Figure 6a, the $\mathrm{CC}$ and $\mathrm{CV}$ output of the WPT system will not be affected. In the case of the shortening of transmission distances in Fig. $6 \mathrm{~b}$ and the lateral misalignment of the secondary coil in Fig. 6c, the coupling coefficient will change, consequently, from (11) the output current will vary, and from (13) the output voltage will change. Figure 7 shows the coupling $k$ of the two coils at different transmission distance. According to the coil parameters in Table 1, the coupling $k$ between two coils at different distances is calculated by a useful inductance calculator software Inca [9]. It can be seen that the farther the distance, the smaller the coupling $k$.

Table 1. Parameters of WPT system

\begin{tabular}{lll}
\hline \hline Component & Symbol & Value \\
\hline Transmitting Coil & Lp & $67.89 \mathrm{uH}$ \\
& Cp & $0.2 \mathrm{uF}$ \\
& Rw1 & $0.5 \mathrm{ohm}$ \\
& $\mathrm{fp}$ & $43.2 \mathrm{kHz}$ \\
& turns coil & 17 \\
& inner diameter & $12 \mathrm{~cm}$ \\
& outer diameter & $22.5 \mathrm{~cm}$ \\
Receiving Coil & Ls & $66.15 \mathrm{uH}$ \\
& Cs & $0.2 \mathrm{uF}$ \\
& Rw2 & $0.5 \mathrm{ohm}$ \\
& Fs & $43.2 \mathrm{kHz}$ \\
& turns coil & 17 \\
& inner diameter & $12 \mathrm{~cm}$ \\
& outer diameter & $22.5 \mathrm{~cm}$ \\
\hline \hline
\end{tabular}

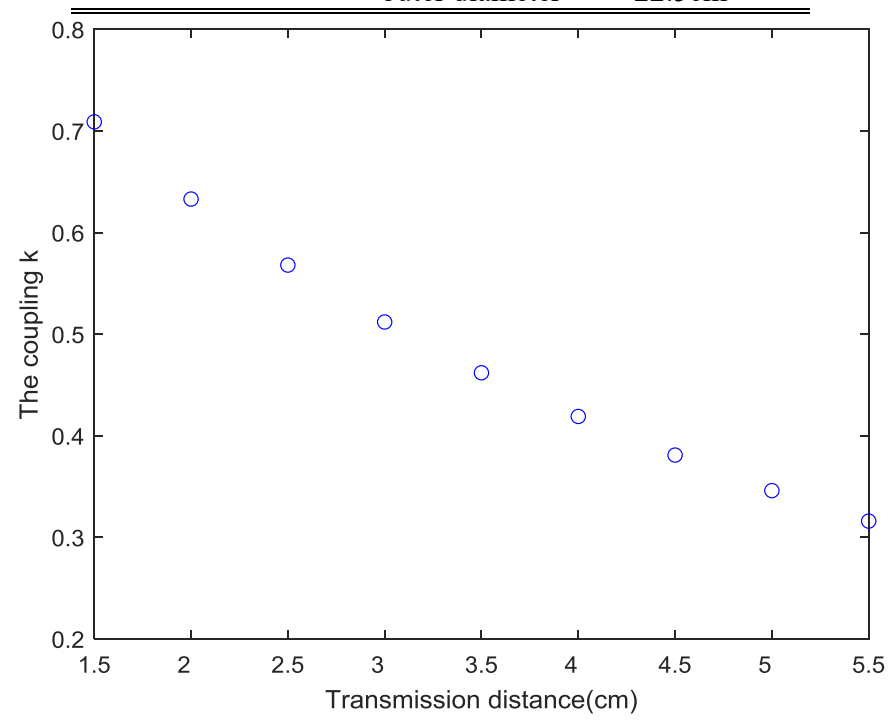

Fig. 7. The coupling coefficient $k$ at different transmission distance.

When the position of the secondary coil is changed, the coupling $k$ will change. Measures should be taken to ensure that the WPT system can achieve CC and CV output. In CC mode, 
from (11) the input voltage might be changed correspondingly to keep the output current constant. In CV mode, from (13) and (14) the system operation frequency might be varied to keep the output voltage constant. In this study, the coupling $k$ is estimated by using the transconductance amplitude equation, and then the input voltage or working frequency are adjusted respectively to achieve $\mathrm{CC}$ or $\mathrm{CV}$ output. This idea will be presented clearly in next section.

\section{1) Estimation of coupling coefficient in the WPT system}

The transconductance is the ratio of the output current to the input voltage. From (1), the transconductance (26) can be derived. The transconductance amplitude equation (27) can be derived from (26).

Coupling coefficient estimation requires theoretical and measured output current and output voltage. The load resistance can be known by measuring the output current and output voltage in the circuit. The values of the primary inductance and capacitance, the secondary inductance and capacitance, the input voltage and the working frequency are known. These parameters are substituted into the transconductance amplitude equation as shown in (27), and the coupling $k$ can be obtained.

Since $\mathrm{M}$ in the transconductance amplitude equation (27) is to the eighth power, the coupling $k$ obtained has eight solutions. Three of the eight solutions have different roots, and the rest are multiple roots. Therefore, the three different $k$ values need to be selected to get the real $k$. These three different $k$ values are substituted into the current equation as shown in (28), to obtain the primary and secondary current, which are compared with the values measured. If they are equal, and then the real coupling $k$ is found.

$$
\begin{aligned}
& \frac{I_{2}}{\mathrm{U}_{\text {in }}}=\frac{j \omega M}{\left(j \omega L_{p}+\frac{1}{j \omega C_{p}}\right)\left(j \omega L_{s}+\frac{1}{j \omega C_{s}}+R_{L, e q}\right)+\omega^{2} M^{2}} \\
& \left\{\begin{array}{l}
\left|\frac{I_{2}}{\mathrm{U}_{i n}}\right|=\sqrt{\frac{a^{2}+b^{2}}{\left[-c^{2}-d^{2}\right]^{2}}} \\
a=-\omega M R_{L, e q}\left(\omega L_{p}-\frac{1}{\omega C_{p}}\right) \\
b=\omega M\left(\omega L_{p}-\frac{1}{\omega C_{p}}\right)\left(\omega L_{s}-\frac{1}{\omega C_{s}}\right)-\omega^{3} M^{3} \\
c=\left(\omega L_{p}-\frac{1}{\omega C_{p}}\right) R_{L, e q} \\
d=\left(\omega L_{p}-\frac{1}{\omega C_{p}}\right)\left(\omega L_{s}-\frac{1}{\omega C_{s}}\right)-\omega^{2} M^{2}
\end{array}\right. \\
& \left\{\begin{array}{l}
I_{1}=\frac{U_{i n}}{\left(j \omega L_{p}+\frac{1}{j \omega C_{p}}\right)+\frac{(\omega M)^{2}}{j \omega L_{s}+\frac{1}{j \omega C_{s}}+R_{L, e q}}} \\
I_{2}=\frac{j \omega M}{j \omega L_{s}+\frac{1}{j \omega C_{s}}+R_{L, e q}} I_{1}
\end{array}\right.
\end{aligned}
$$

For above method, the coupling $k$ at different transmission distances of two coils is calculated by Inca first. According to the coil parameters in Table 1, the transconductance amplitude equation method is used to estimate the coupling $k$ by MATLAB. Two working frequency, the resonant frequency $43.2 \mathrm{kHz}$ and the above resonance frequency $56.6 \mathrm{kHz}$, were selected to verify the method. Figure 8 compares the Inca value and the estimated value of the coupling $k$ at different distances under the operating frequency of $43.2 \mathrm{kHz}$ or $56.6 \mathrm{kHz}$. It can be seen that the coupling $k$ estimated by the transconductance amplitude equation method are in general agreement with the Inca value, indicating that the transconductance equation method is feasible.

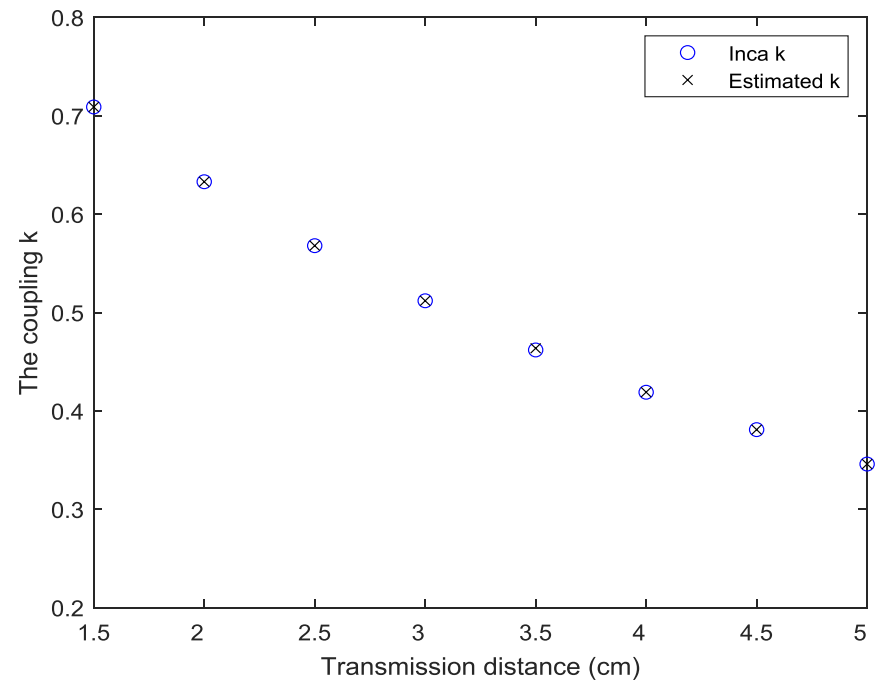

(a)

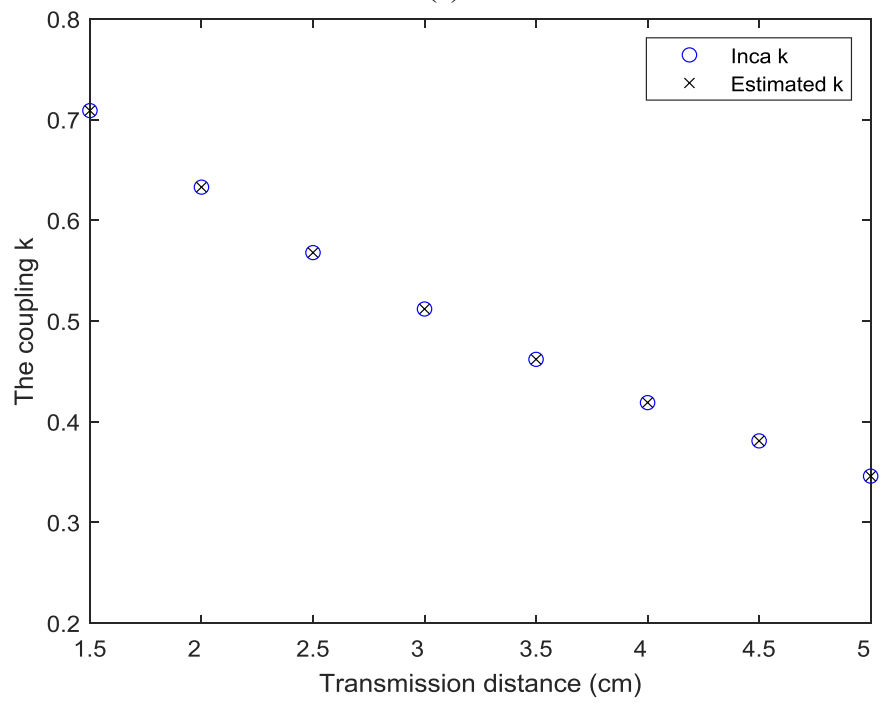

(b)

Fig. 8. Comparison of the Inca values and the estimated values of the coupling $k$ at different transmission distance. (a) Operating at the resonant frequency of $43.2 \mathrm{kHz}$; (b) Operating at the above resonance frequency of $56.6 \mathrm{kHz}$. 


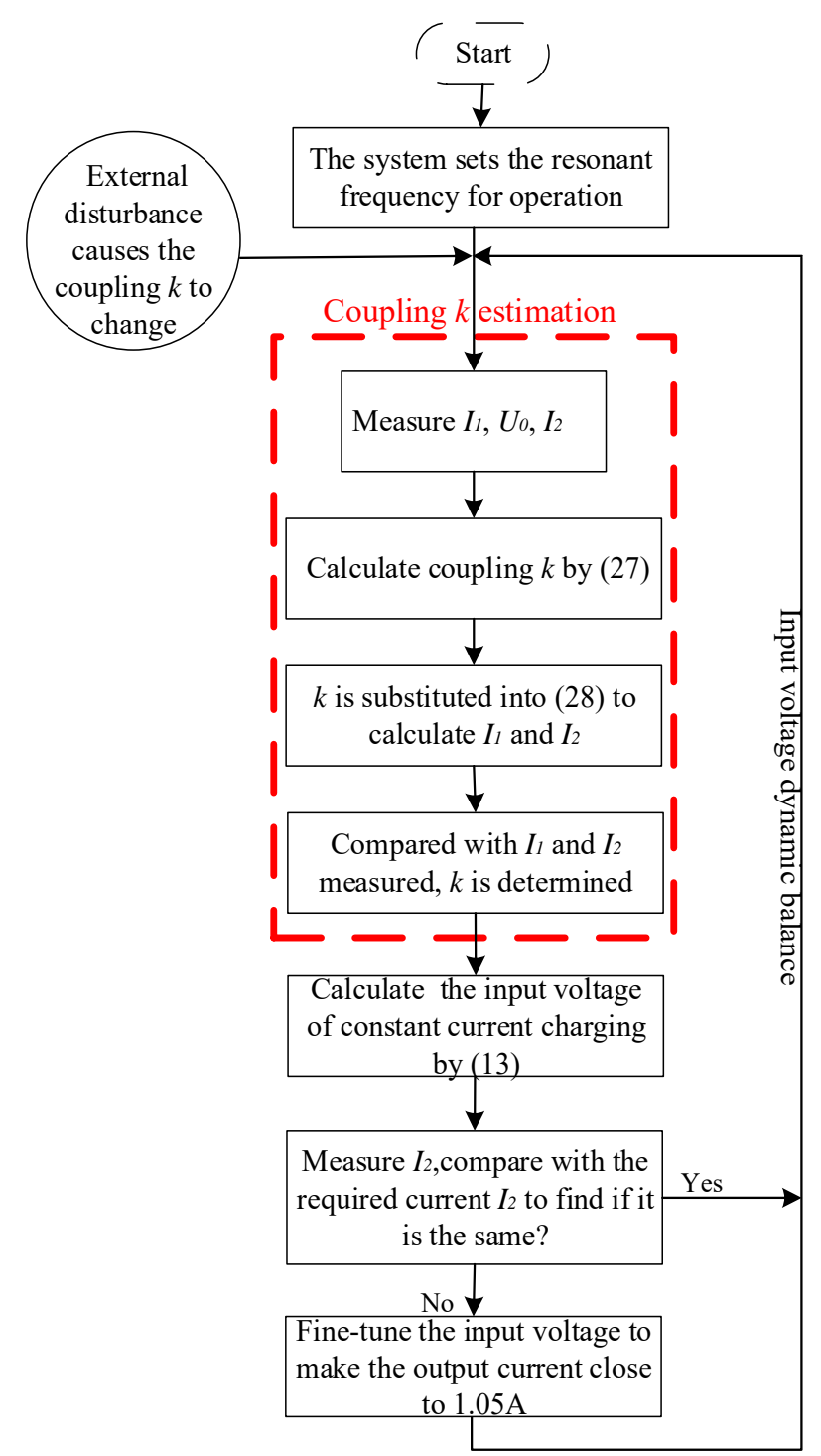

Fig. 9. Flow chart of input voltage regulation in the CC mode.

2) Implementation of CC Output under Misalignment or Range Variation by Adaptive Regulation

In $\mathrm{CC}$ mode, when the coil is under misalignment or range variation, the flow chart of dynamic input voltage regulation is shown in Fig. 9. First, the coupling $k$ is estimated. Next, calculate the input voltage from (13). There are uncertainties in the system circuit description (1) because of the existence of non-ideal coils, and the input voltage should be fine-tuned. Measure $I_{2}$ and compare it with the desired CC output. If the measured $I_{2}$ differs from the desired value, the input voltage is fine-tuned to make the output current more accurate.

\section{3) Implementation of CV Output under Misalignment or} Range Variation by Adaptive Regulation

In $\mathrm{CV}$ mode, when the coil is under misalignment or range variation, the flow chart of dynamic frequency regulation is shown in Fig. 10. The coupling $k$ is estimated first. After the coupling $k$ is determined, the working frequency at this point is calculated from (16), and the working frequency is fine-tuned to make the output voltage closer to $8 \mathrm{~V}$.

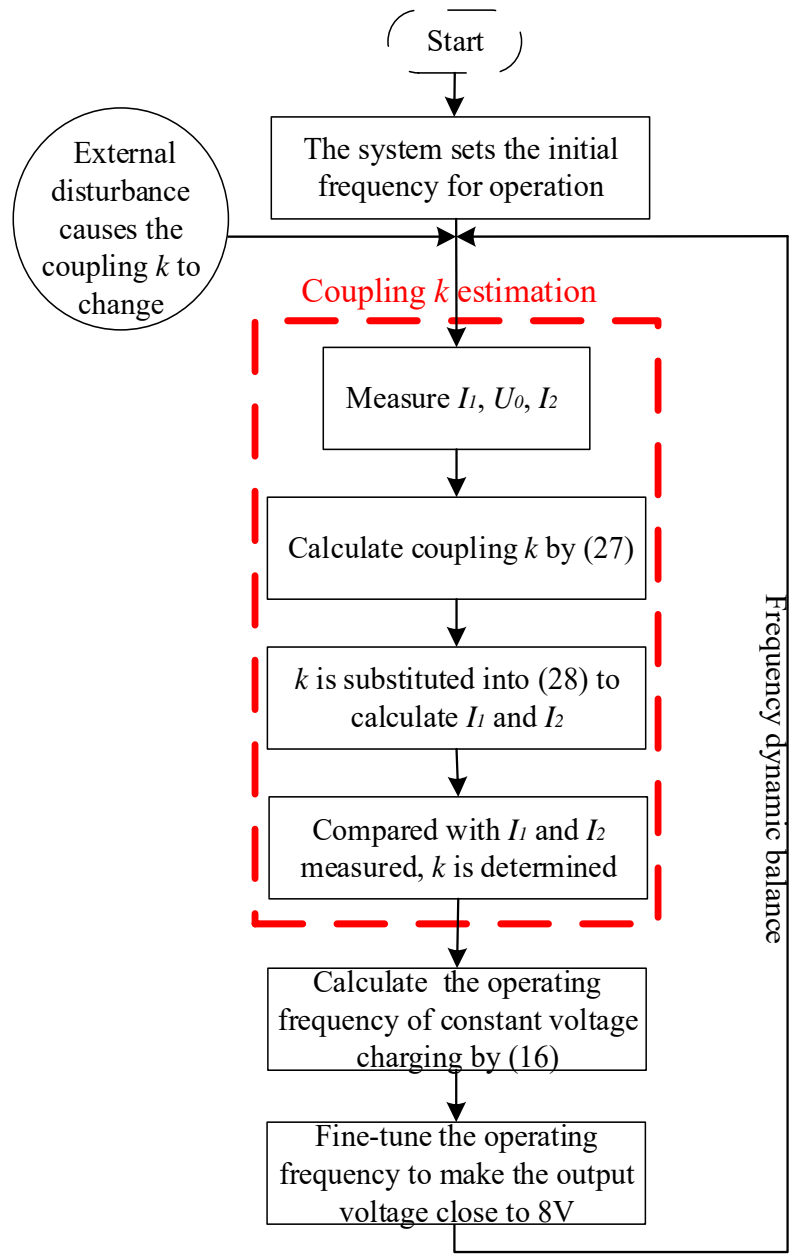

Fig. 10. Flow chart of working frequency dynamic regulation in $\mathrm{CV}$ mode.

4) Charging Mode Switching Strategy

For a fixed battery, assume that its nominal voltage is $U_{\max }$ .When the battery is in a low voltage state, the voltage is $U_{\min }$. During the charging process, the charging voltage of the battery is $U_{0}$ and the charging current is $I_{0}$. The battery acts as a variable resistor with a value of $R_{L}=U_{0} / I_{0}$. In the CC charging stage, the battery is charged with a constant current, and the voltage of the battery increases with charging time. When the charging voltage $U_{0}$ is increased to $U_{\max }$, the charging process is converted to $\mathrm{CV}$ mode. During the $\mathrm{CV}$ charging process, the charging voltage of the battery remains unchanged, the internal resistance of the battery gradually increases, and the charging current gradually decreases until the battery is full [17]. The change of the resistance of the battery during the whole process is shown in (29).

$$
\left\{\begin{array}{l}
\frac{U_{0}}{I_{c c}} \leq R_{L} \leq \frac{U_{\max }}{I_{c c}} \\
\frac{U_{\max }}{I_{c c}} \leq R_{L} \leq \infty
\end{array}\right.
$$

In this study, the $\mathrm{CC}$ output of battery charging is set as $1.05 \mathrm{~A}$, and the $\mathrm{CV}$ output is set as $8 \mathrm{~V}$. When the battery voltage is lower than the maximum charging voltage of $8 \mathrm{~V}$, the current controller is activated to charge the battery with the output 
current of $1.05 \mathrm{~A}$ in $\mathrm{CC}$ mode. When the battery voltage reaches the maximum charging voltage, the controller can automatically switch to CV charging mode.

\section{EXPERIMENTAL RESULTS}

Firstly, the experimental WPT system and its parameters are given. In the second section, the experimental results under ideal coil alignment are presented. The third section describes the experiment of realizing $\mathrm{CC}$ and $\mathrm{CV}$ output when the transmission distance shortens $1 \mathrm{~cm}$. The last section gives the experiment of realizing $\mathrm{CC}$ and $\mathrm{CV}$ output when the secondary coil has $3 \mathrm{~cm}$ lateral misalignment.

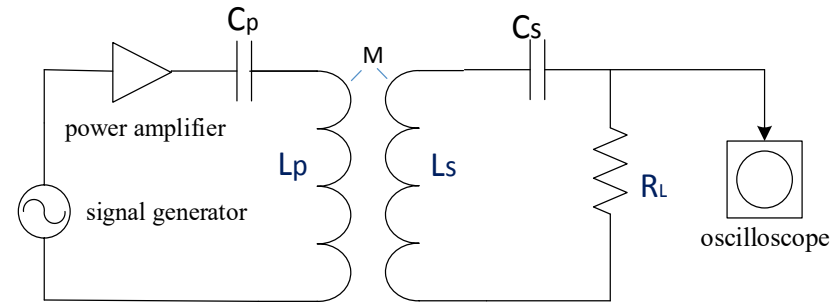

Fig. 11. Schematic diagram of the experimental WPT system.

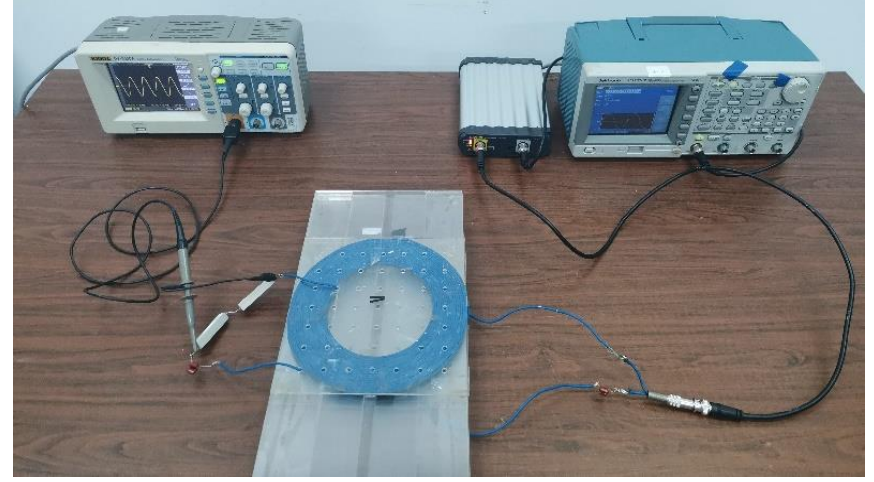

Fig. 12. The experimental platform of the suggested WPT system.

\section{A. Experimental Platform of the WPT System}

Based on the previous analysis and design, the schematic diagram of the experimental WPT system is shown in Fig. 11. The signal generator provides energy to the transmitting coil of the WPT system. A power amplifier amplifies the input voltage provided by the signal generator. Capacitance $L_{p}$ and $L_{S}$ compensate the reactive power of the circuit to improve its efficiency. The waveform of the load is measured by an oscilloscope.

The experimental platform is shown in Fig. 12, consists of a signal generator (Tektronix: AFG3102), a power amplifier (Rigol:PA1011), an oscilloscope (Rigol:DS1302), two coils with the AWG16 wire, resistors, and capacitors [10]. $4 \Omega$ to $12 \Omega$ resistors at an interval of $0.5 \Omega$ should be prepared before experiment. The key parameters in Table 1 are measured by a LCR meter (GW Instek: LCR821) [9]. $R_{W 1}$ includes the internal resistance of $L_{p}$ and $C_{p} . R_{W 2}$ includes the internal resistance of $L_{s}$ and $C_{s}$. The ratio of turns between primary and secondary coils is $17: 17$. The air gap between two coils is $40 \mathrm{~mm}$. The coupling $k$ calculated by software Inca is 0.419 , and the input voltage is $8 \mathrm{~V}$. In the $\mathrm{CC}$ mode, the operating frequency is $43.2 \mathrm{kHz}$, which can realize $1.05 \mathrm{~A} \mathrm{CC}$ charging. In the $\mathrm{CV}$ mode, the operating frequency is $36.2 \mathrm{kHz}$ or $56.6 \mathrm{kHz}$, which can realize $\mathrm{CV}$ charging.

\section{Experimental steps:}

Step 1: The experimental platform is built, and the signal generator, the power amplifier, the capacitor $L_{P}$ and the inductor $C_{P}$ are connected in series to form the primary side circuit. The inductor $L_{S}$, the capacitor $C_{S}$ and the resistor are connected in series to form a secondary loop.

Step 2: Perform the experiment at ideal alignment with a $4 \mathrm{~cm}$ transmission distance. The experimental results are shown in Section 3.2. The ideal output current in CC mode is $1.05 \mathrm{~A}$, and the ideal output voltage in $\mathrm{CV}$ mode is $8 \mathrm{~V}$.

Step 3: Change the transmission distance from $4 \mathrm{~cm}$ to $3 \mathrm{~cm}$. Switch on the circuit according to the aligned experimental parameters. The load resistance is $5 \Omega$. Measure electrical parameters and it is found that the input current is $0.46 \mathrm{~A}$, the output voltage is 4.37 Vand the output current is $0.874 \mathrm{~A}$.

Step 4: These measured data were manually inserted into the amplitude equation (27) and to find the coupling $\mathrm{k}$ by MATLAB. $\mathrm{k}$ obtained has eight solutions. Three of the eight solutions have different roots, and the rest are multiple roots. They are $0.5032,0.00002086$ and 0.01025 . These three different $\mathrm{k}$ values are substituted into the current equation (28), to obtain the primary and secondary current, which are compared with the values measured. Then the true coupling $\mathrm{k}$ is found to be 0.5032 .

Step 5: In CC mode, according to (13), the input voltage should be $9.73 \mathrm{~V}$. Then adjust manually the input voltage of the signal generator to $9.73 \mathrm{~V}$ and the output current measured is now $1 \mathrm{~A}$. Because it is $0.05 \mathrm{~A}$ lower than the required output current, the input voltage is fine-tuned manually to $10.02 \mathrm{~V}$, bringing the output current to $1.05 \mathrm{~A}$. The input voltage regulation in the $\mathrm{CC}$ mode is completed at this time.

Step 6: In CV mode, according to (16), the above resonance frequency should be $61.3 \mathrm{kHz}$. Then adjust manually the working frequency of the signal generator to $61.3 \mathrm{kHz}$. and the output voltage measured is now $7.5 \mathrm{~V}$. Because it is $0.5 \mathrm{~V}$ lower than the required output voltage, the working frequency is fine-tuned manually to $60.8 \mathrm{kHz}$, bringing the output voltage to $7.97 \mathrm{~V}$ (It is the value closest to the desired output voltage). The working frequency dynamic regulation in $\mathrm{CV}$ mode is completed at this time. Repeat the above operation at the below resonance frequency.

Step 7: When the secondary coil has $3 \mathrm{~cm}$ lateral misalignment, repeat steps 2 through 5 above.

\section{B. CC/CV Mode Charge at Alignment}

Figure 13 shows the curve of output current of the WPT system relative to frequency under variable load in the CC mode at alignment. It can be seen that the experimental results are in general agreement with the theory. Figure 13 shows the comparison between theoretical value and experimental value, 
with lines representing theoretical values and points representing experimental values. In the low frequency stage, the experimental value and the theoretical value have a high consistency. The experimental value is higher than the theoretical value in the intermediate frequency stage. Theoretical value is higher than experimental value at high frequency stage. It can realize constant current charging at $43.2 \mathrm{kHz}$ under different loads.

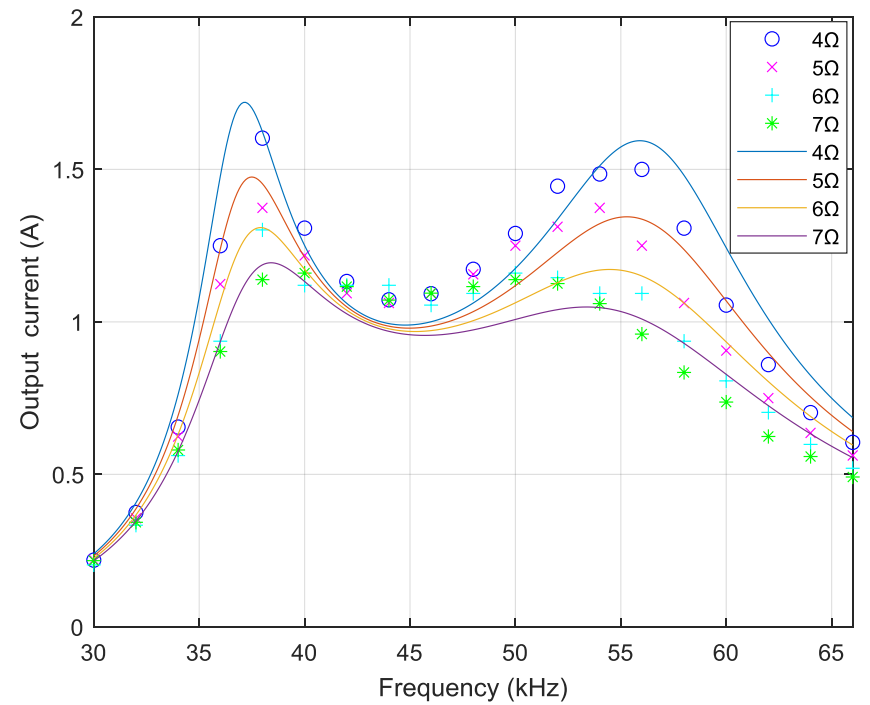

Fig. 13. The curve of output current relative to frequency at alignment.

Figure 14 shows the curve of output voltage relative to frequency under variable load in the $\mathrm{CV}$ mode at alignment. Lines represent theoretical values and points represent experimental values. The experimental results are largely consistent with the theory. It can also be seen from Fig. 14 that $\mathrm{CV}$ charging can be realized at $36.2 \mathrm{kHz}$ and $56.6 \mathrm{kHz}$.

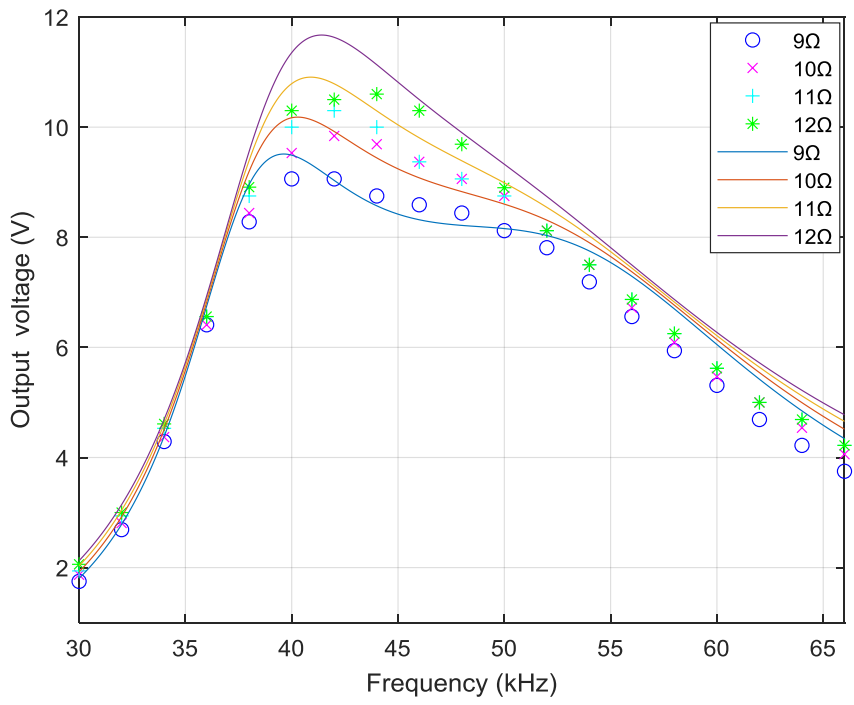

Fig. 14. The curve of output voltage relative to frequency at alignment.

The errors in Fig. 13 and Fig. 14 are mainly due to circuit model errors, oscilloscope and amplifier errors used in the experiment.

The waveform of input voltage and output voltage is shown in Fig. 15 at two CV operating frequencies. The blue waveform represents the input voltage and the yellow waveform represents the output voltage. It can be seen from Fig. 15 that the input voltage and the output voltage are in phase at the above resonance frequency $56.2 \mathrm{kHz}$. At the below resonance frequency $43.2 \mathrm{kHz}$, the input voltage and output voltage are out of phase. These observations consist with former theoretical analysis (17) and (18).

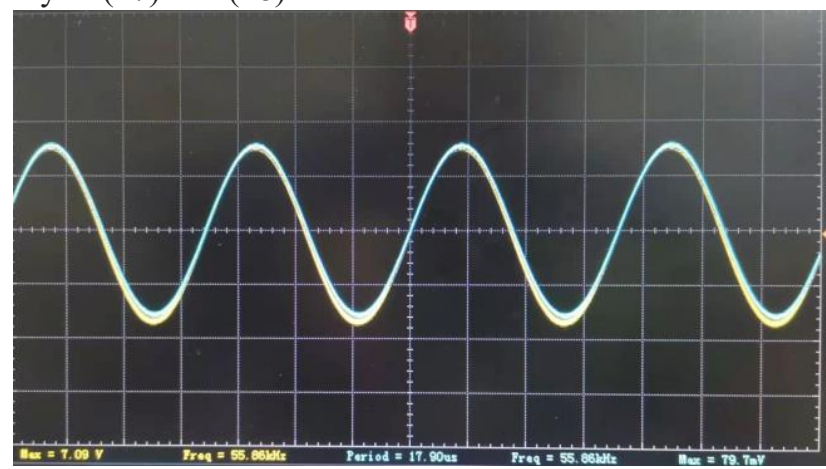

(a)

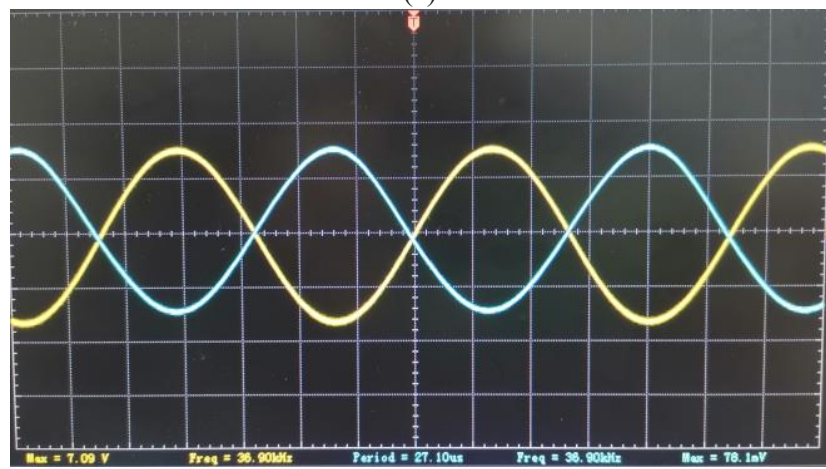

(b)

Fig. 15. The waveform of input voltage and output voltage. The blue waveform represents the input voltage and the yellow waveform represents the output voltage. (a) At the above resonance frequency $56.6 \mathrm{kHz}$; (b) at the below resonance frequency $36.2 \mathrm{kHz}$.

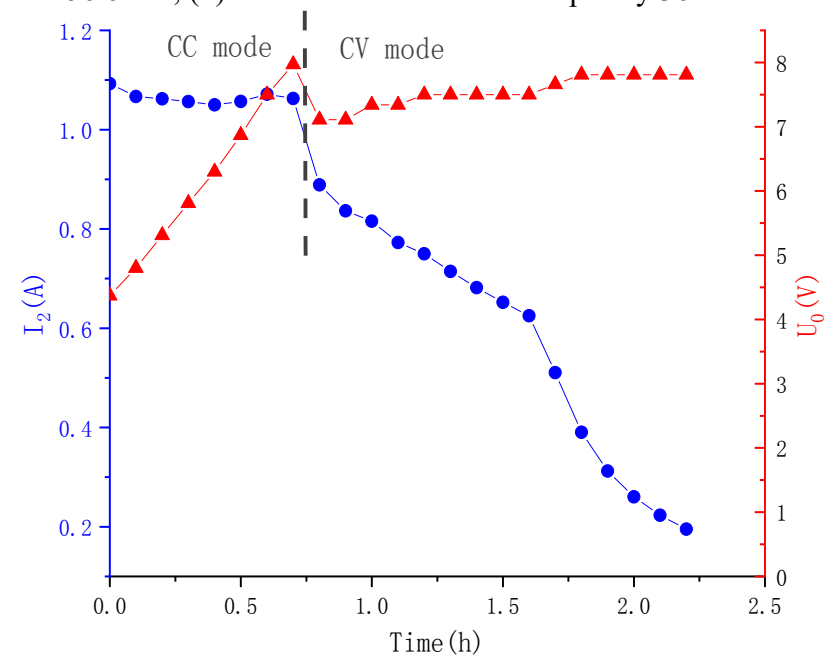

Fig. 16. Charging profile during the whole charging process.

The whole charging profile with the charging voltage and current versus time is shown in Fig. 16. Here is the simulation of a battery charging process over time, and the battery is simulated by resistance. Figure 16 shows that the maximum power can be up to $8.4 \mathrm{~W}$. During the whole charging process, the efficiency measurement from the input end to the load is shown in Fig. 17. A $1 \Omega$ resistance is added in the primary side 
to measure the input current. As can be seen from Fig. 17, on the left of the dotted line is the system efficiency of the CC mode, which increases with the charging time. On the right of the dotted line is the system efficiency of the CV mode. The system efficiency decreases gradually with time. The maximum efficiency of $91.3 \%$ is achieved when the CC mode is converted to the $\mathrm{CV}$ mode.

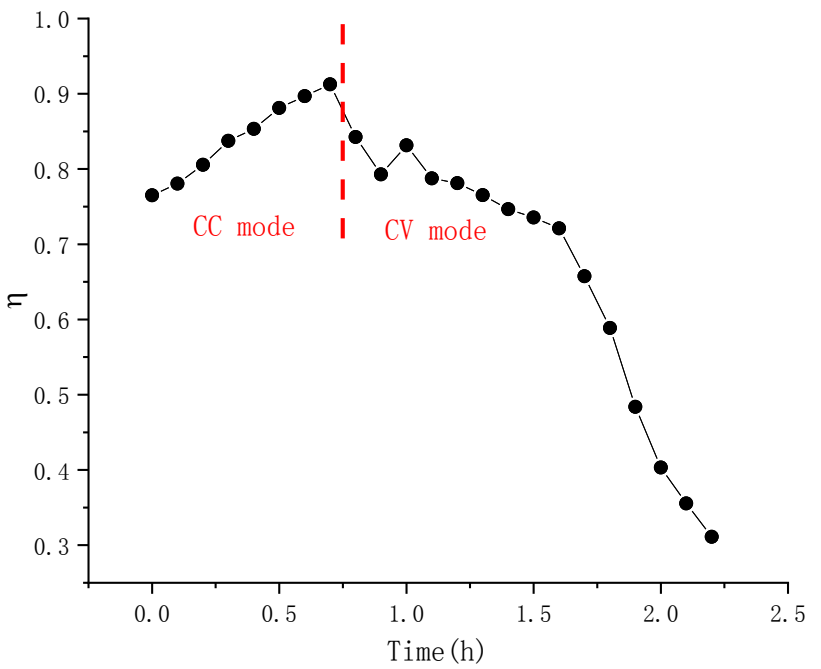

Fig. 17. Measured efficiencies of the WPT system at CC and CV modes of charging.

\section{C. $C C / C V$ Mode Charge under Range Variation}

Firstly, the output results of $\mathrm{CC}$ and $\mathrm{CV}$ without dynamic adjustment are given when the transmission distance changes from $4 \mathrm{~cm}$ to $3 \mathrm{~cm}$. Secondly, the output diagram of CC and CV after dynamic adjustment is presented when the distance shortens. Finally, the experimental coupling $k$ is compared with the theoretical value at different transmission distances.

When the transmission distance changes from original $4 \mathrm{~cm}$ to $3 \mathrm{~cm}$, the current and voltage characteristics of the charging process are shown in the Fig. 18. The curves in Fig. 18 represent $\mathrm{CC}$ output of $1.05 \mathrm{~A}$ and $\mathrm{CV}$ output of $8 \mathrm{~V}$ that are specific to fixed batteries. The CC mode resistance is $4 \Omega$ to $7.5 \Omega$, and the working frequency is $43.2 \mathrm{kHz}$. The $\mathrm{CV}$ mode resistance is $7.5 \Omega$ to $12 \Omega$, and the working frequency is $36.2 \mathrm{kHz}$ or $56.6 \mathrm{kHz}$. When the secondary side moves downward $1 \mathrm{~cm}$, the coupling $k$ of the system increases from 0.419 to 0.503 . The output current can be obtained from (13) and the output voltage can be obtained from (15), as shown in Fig. 19. It can be seen from Fig. 16a that the output current decreases with the coupling $k[6]$, so the current output in the experimental $\mathrm{CC}$ mode is smaller than the required current as shown in Fig. 18a. Figure 19b shows that the output voltage increases with the coupling $k$, so the output voltage in the experiment is higher than the theoretical value as shown in Fig.18b. Consequently, the WPT system cannot achieve a CV output under the operating frequency of $36.2 \mathrm{kHz}$ or $56.6 \mathrm{kHz}$ when the transmission distance shortens $1 \mathrm{~cm}$.

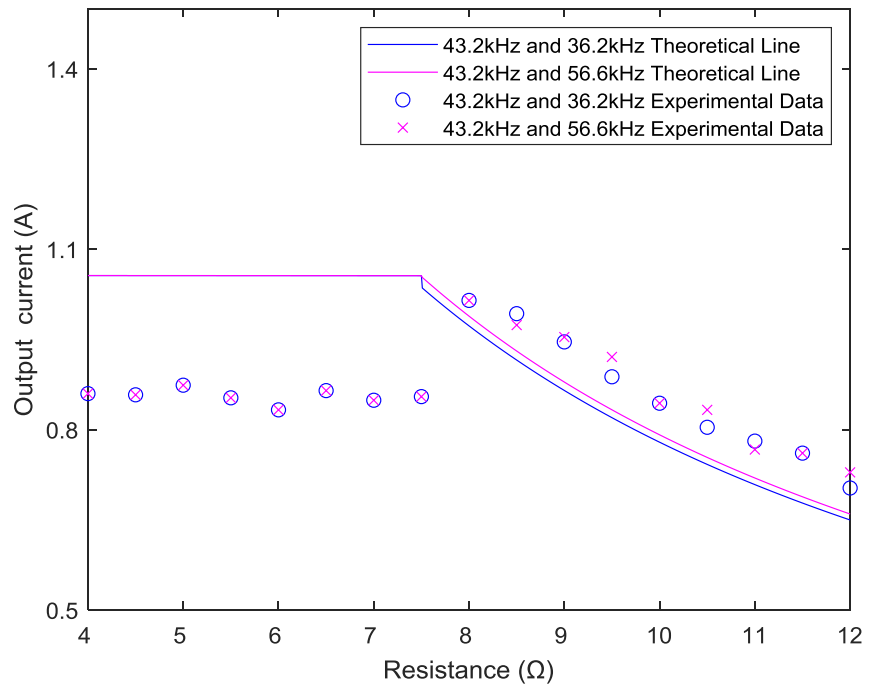

(a)

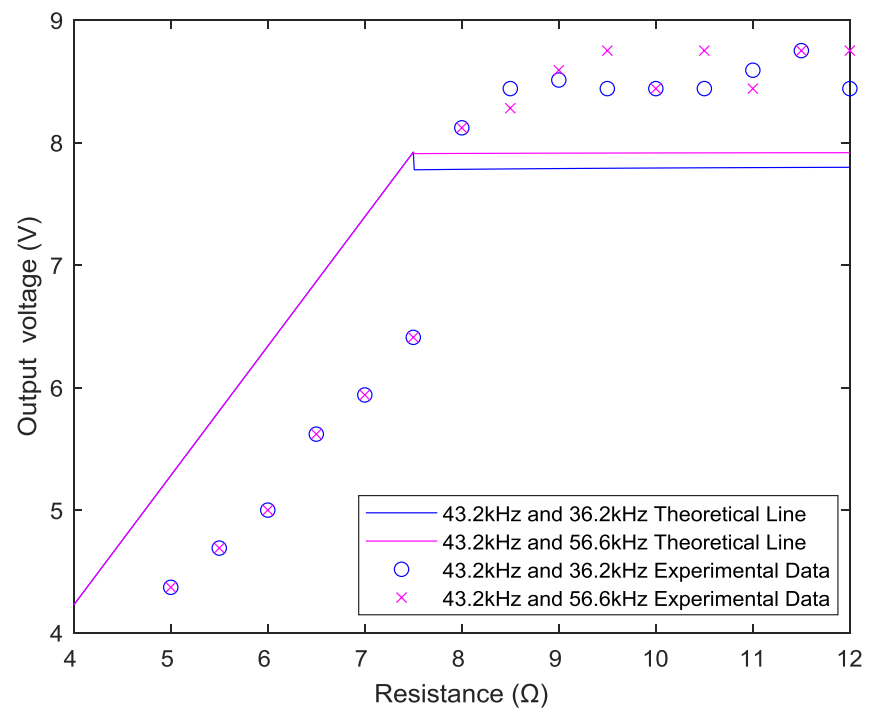

(b)

Fig. 18. The current (a) and voltage (b) characteristics of the charging process without dynamic adjustment when transmission distance decreased from $4 \mathrm{~cm}$ to $3 \mathrm{~cm}$.

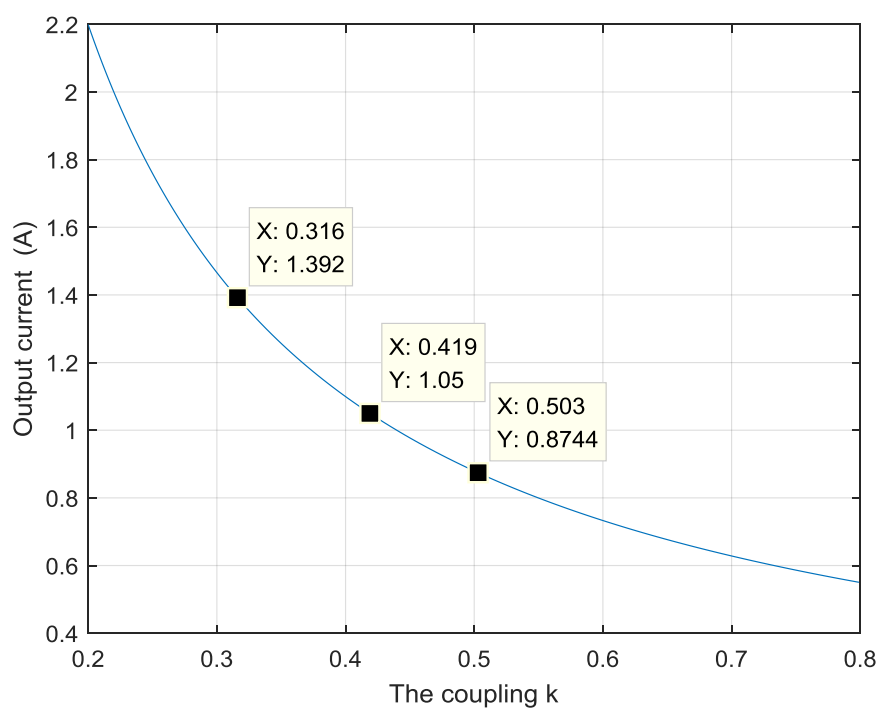

(a) 


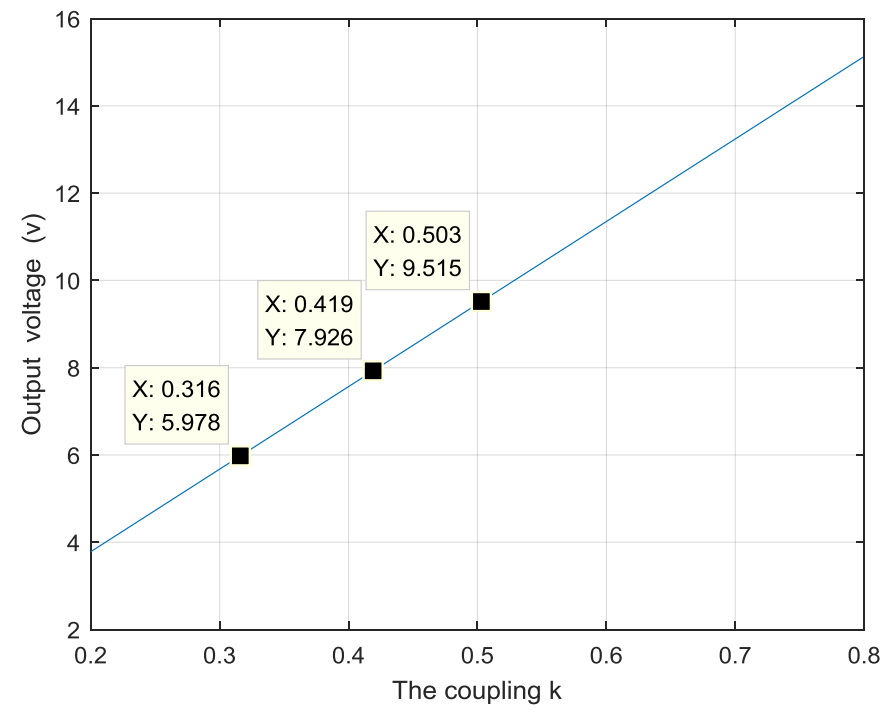

(b)

Fig. 19. (a)The curve of output current relative to the coupling $k$ at a $43.2 \mathrm{kHz}$ working frequency; (b) The curve of output voltage relative to the coupling $k$ at a $56.6 \mathrm{kHz}$ working frequency

To tackle the range variation, $\mathrm{CC}$ and $\mathrm{CV}$ output are achieved by adjusting the input voltage and the CV working frequency as shown in the Fig.20. After adjustment, when the transmission distance changes from $4 \mathrm{~cm}$ to $3 \mathrm{~cm}$, the current and voltage characteristics during charging can meet the required requirements. Since the coupling $k$ estimated at this time is 0.503 , in CC mode, the input voltage should be $9.73 \mathrm{~V}$ according to (13). Then adjust manually the input voltage of the signal generator to $9.73 \mathrm{~V}$ and the output current measured is now $1 \mathrm{~A}$. Because it is $0.05 \mathrm{~A}$ lower than the required output current, the input voltage is fine-tuned manually to $10.02 \mathrm{~V}$, bringing the output current to $1.05 \mathrm{~A}$. In $\mathrm{CV}$ mode, according to $\omega_{v 1}$ in (16), the above resonance frequency should be $61.3 \mathrm{kHz}$. Then adjust manually the working frequency of the signal generator to $61.3 \mathrm{kHz}$, and the output voltage measured is now $7.5 \mathrm{~V}$. Because it is $0.5 \mathrm{~V}$ lower than the required output voltage, the working frequency is fine-tuned manually to $60.8 \mathrm{kHz}$, bringing the output voltage to $7.97 \mathrm{~V}$ (It is the value closest to the desired output voltage). Therefore, the $\mathrm{CV}$ output is realized by adjusting the working frequency of constant voltage to $35.5 \mathrm{kHz}$ or $60.8 \mathrm{kHz}$. The intermediate jump is because the operating frequency of CC mode and CV mode is different, and the current and voltage output will change after switching. As shown in Fig. 4, the output current at $43.2 \mathrm{kHz}$ is $0.005 \mathrm{~A}$ lower than that at $56.6 \mathrm{kHz}$ and $0.013 \mathrm{~A}$ higher than that at $36.2 \mathrm{kHz}$, so a jump is a normal phenomenon.

During the experiment, the transmission distance of the two coils was changed between $1.5 \mathrm{~cm}$ and $5.5 \mathrm{~cm}$. Fig. 21 compares the coupling $k$ estimated during different transmission distance with the theoretical coupling $k$ and the Inca $k$ in the $\mathrm{CV}$ mode. It can be seen that when the transmission distance is between $2.5 \mathrm{~cm}$ and $5.5 \mathrm{~cm}$, the error between the experimental coupling $k$ and the theoretical value is small, but the error between the experimental coupling $k$ and the theoretical value is large when the transmission distance is between $1.5 \mathrm{~cm}$ and $2.5 \mathrm{~cm}$. Because the coil is not ideal, the measured result is closer to the real one, so the operation frequency fine-tuning procedure is needed, Fig. $9 \& 10$.

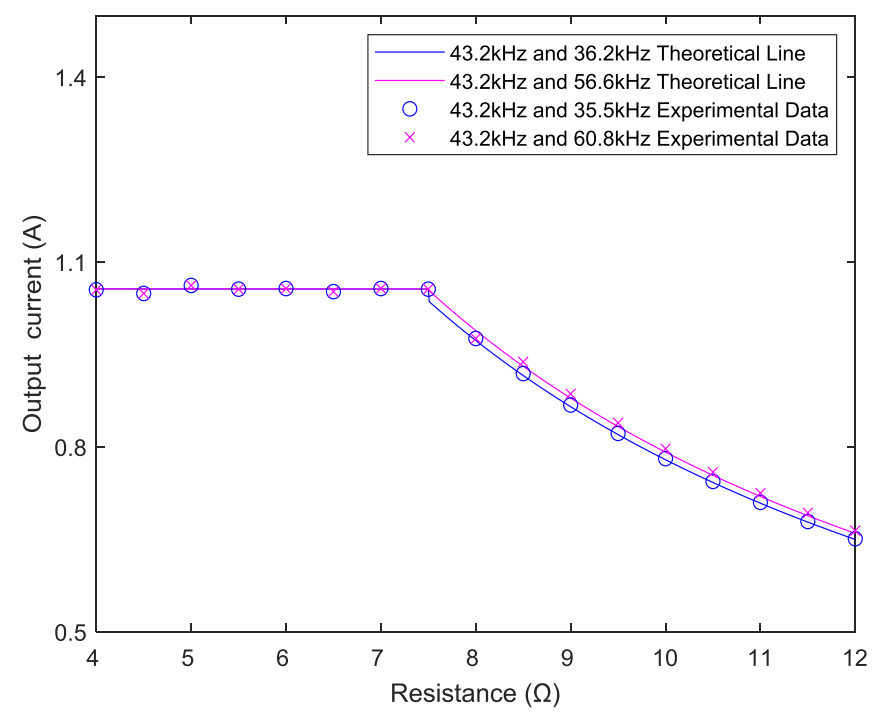

(a)

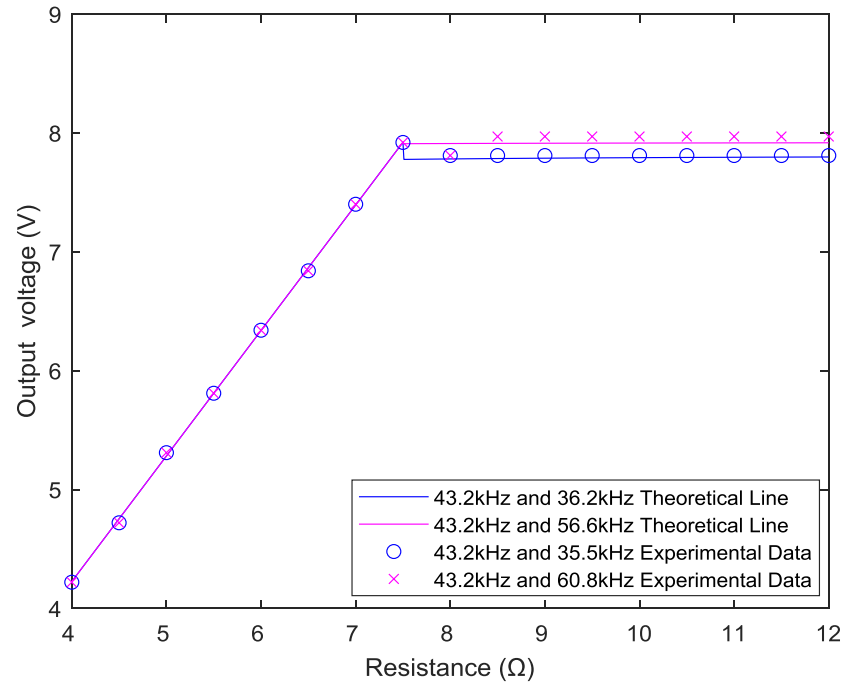

(b)

Fig. 20. The current (a) and voltage (b) characteristics of the charging process with dynamic adjustment when transmission distance decreased from $4 \mathrm{~cm}$ to $3 \mathrm{~cm}$.

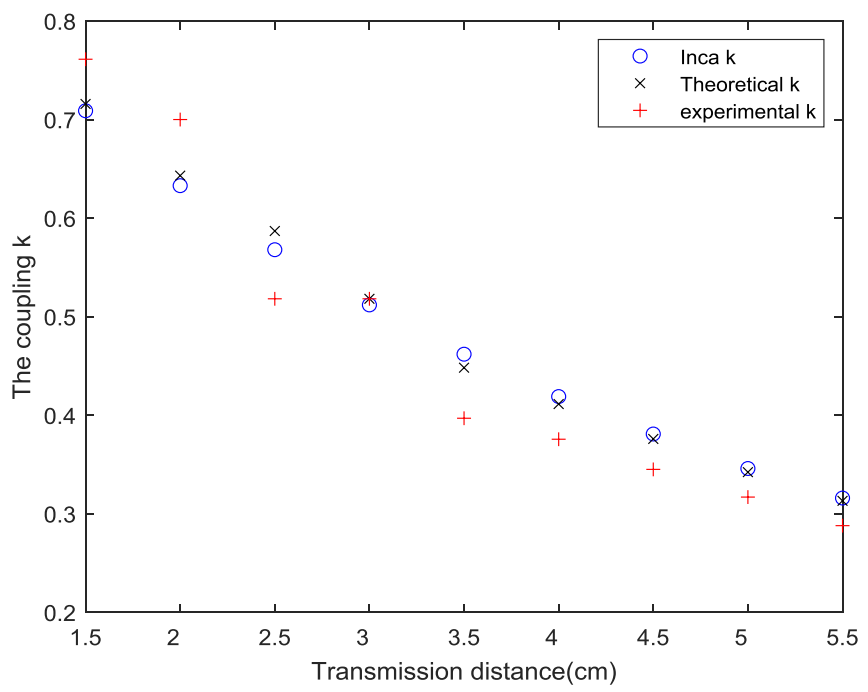

(a) 


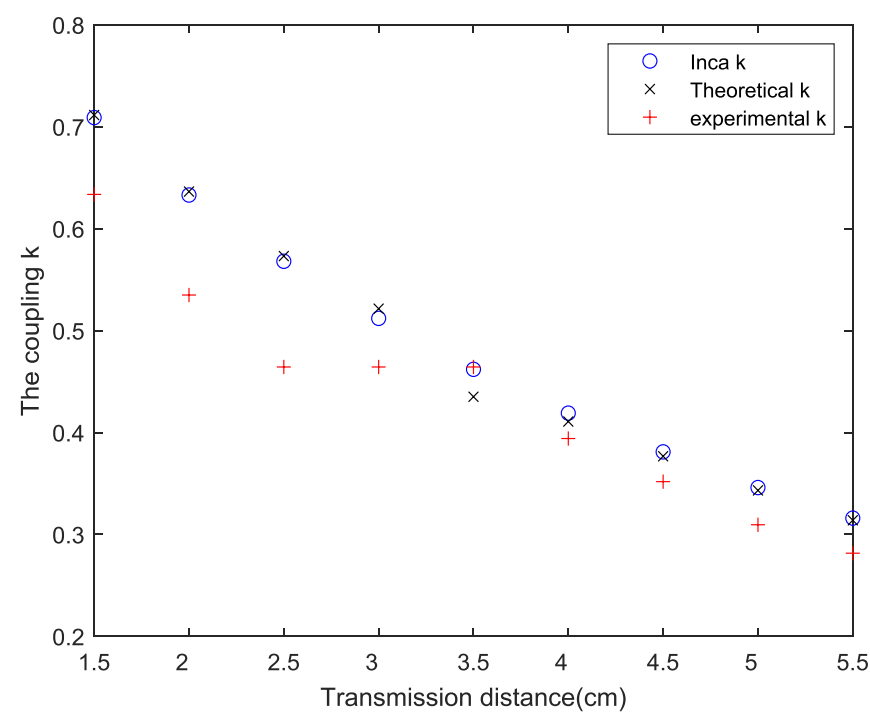

(b)

Fig. 21. Theoretical and experimental values of the coupling $\mathrm{k}$ at different transmission distance. (a) Operating frequency of $36.2 \mathrm{kHz}$; (b) Operating frequency of $56.6 \mathrm{kHz}$.

\section{CC/CV Mode Charge under Misalignment}

First, the output results of CC and CV without dynamic adjustment are given when the secondary coil has $3 \mathrm{~cm}$ lateral misalignment. Next, the output diagram of $\mathrm{CC}$ and $\mathrm{CV}$ after dynamic adjustment is presented when the lateral misalignment is $3 \mathrm{~cm}$. Then experimental coupling $k$ at different misalignment is estimated.

When the lateral misalignment is $3 \mathrm{~cm}$, the current and voltage characteristics of the charging process are shown in the Fig. 22. When the secondary coil moves $3 \mathrm{~cm}$ to the right, the coupling $k$ of the system decreases from 0.419 to 0.316 . It can be seen from Fig. 19 that the output current in the experimental $\mathrm{CC}$ mode is larger than that required, and the output voltage in the experiment is lower than that required. In the $\mathrm{CV}$ mode, the $\mathrm{CV}$ output cannot be realized under the operating frequency of $36.2 \mathrm{kHz}$ or $56.6 \mathrm{kHz}$ when the lateral misalignment is $3 \mathrm{~cm}$. Results of adjusting the input voltage and CV working frequency to realize CC and CV output are shown in Fig. 23. Since the coupling $k$ estimated at this time is 0.316 , in CC mode, the input voltage should be $6.11 \mathrm{~V}$ according to (13). Then adjust manually the input voltage of the signal generator to $6.11 \mathrm{~V}$, and the output current measured is now $0.96 \mathrm{~A}$. Because it is $0.09 \mathrm{~A}$ lower than the required output current, the input voltage is fine-tuned manually to $6.72 \mathrm{~V}$, bringing the output current to $1.05 \mathrm{~A}$. In CV mode, according to $\omega_{v 1}$ in (16), the above resonance frequency should be $53.2 \mathrm{kHz}$. Then adjust manually the working frequency of the signal generator to 53.2 $\mathrm{kHz}$, and the output voltage measured is now $7.81 \mathrm{~V}$. Because it is $0.19 \mathrm{~V}$ lower than the required output voltage, the working frequency is fine-tuned manually to $52.1 \mathrm{kHz}$, bringing the output voltage to $8 \mathrm{~V}$. Therefore, the $\mathrm{CV}$ output is realized by adjusting the working frequency of $\mathrm{CV}$ mode to $37.7 \mathrm{kHz}$ or $52.1 \mathrm{kHz}$. The intermediate jump is due to the different operating frequencies of $\mathrm{CC}$ mode and $\mathrm{CV}$ mode, and the output current and voltage will change after switching.

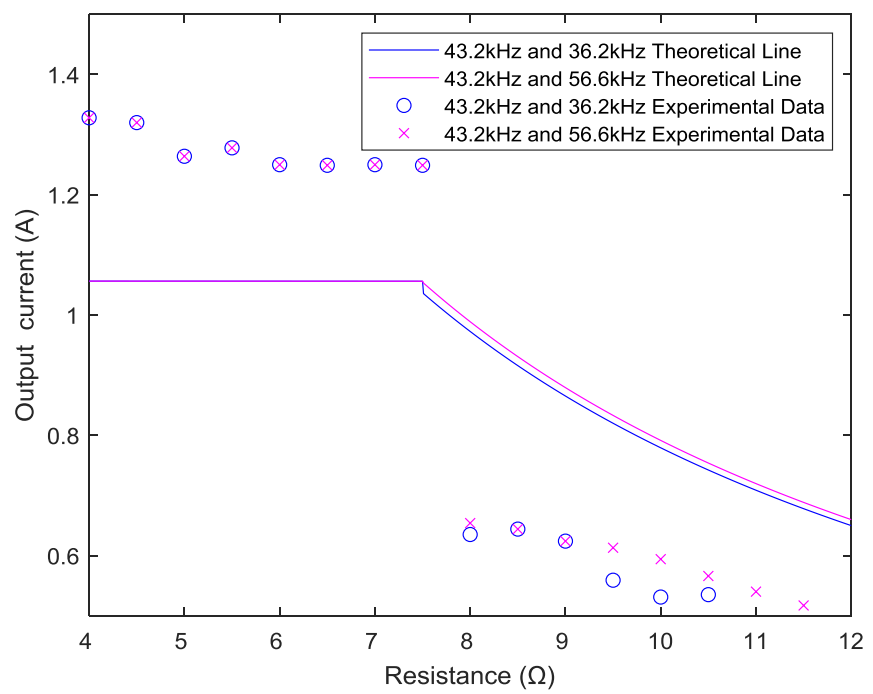

(a)

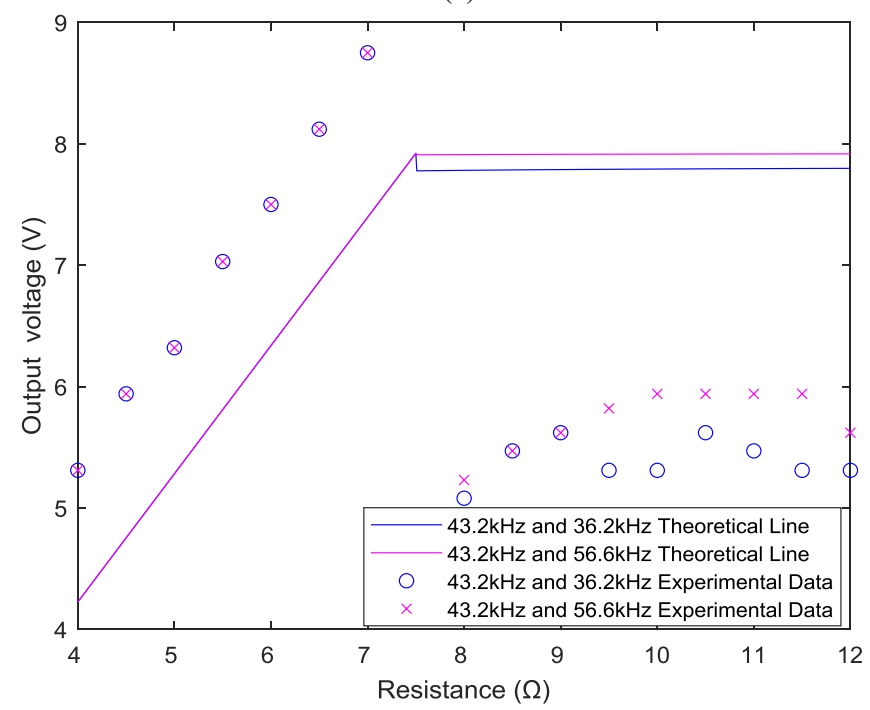

(b)

Fig. 22. The current (a) and voltage (b) characteristics of the charging process without dynamic adjustment when lateral misalignment is $3 \mathrm{~cm}$.

In the misalignment experiment, the misalignment distance of the secondary coil on the $\mathrm{X}$-axis was shifted from $0 \mathrm{~cm}$ to $8 \mathrm{~cm}$, and the misalignment distance on the $\mathrm{Y}$-axis was also shifted from $0 \mathrm{~cm}$ to $8 \mathrm{~cm}$. Since the two coils are concentric circles, the coupling coefficient $k$ measured and calculated in the experiment has roughly the same trend as shown in Fig. 24. As can be seen from Fig. 24, the farther the lateral misalignment distance is, the smaller the coupling $k$ will be.

In the WPT system, the coupling coefficient can be estimated under misalignment or range variation. When the battery is charged wirelessly, it can realize $\mathrm{CC}$ or $\mathrm{CV}$ output charging by estimating the coupling coefficient and then adjusting the input voltage or working frequency with the regulator. 


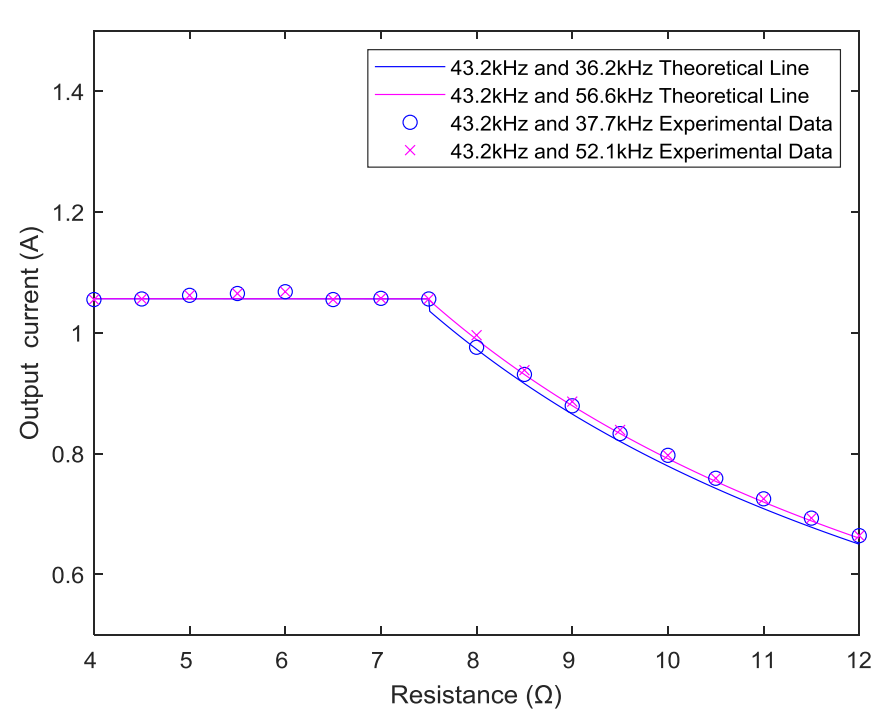

(a)

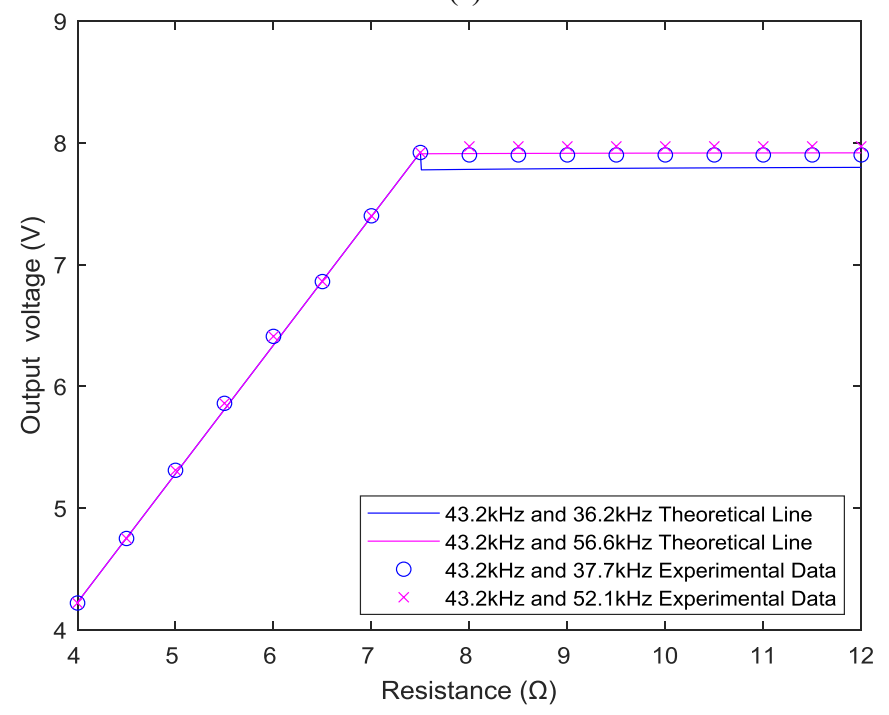

(b)

Fig. 23. The current (a) and voltage (b) characteristics of the charging process with dynamic adjustment when lateral misalignment is $3 \mathrm{~cm}$.

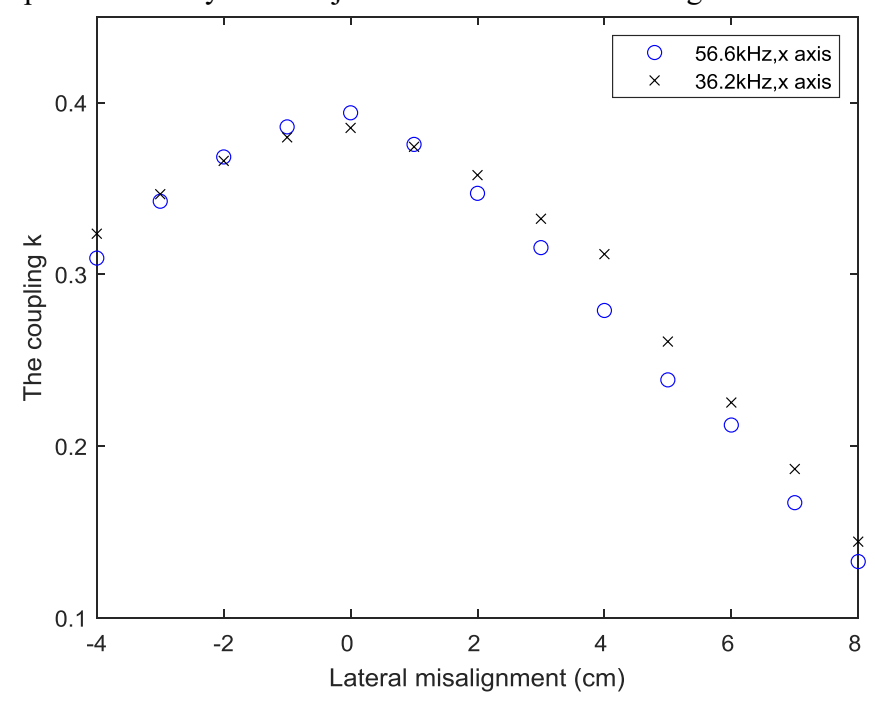

(a)

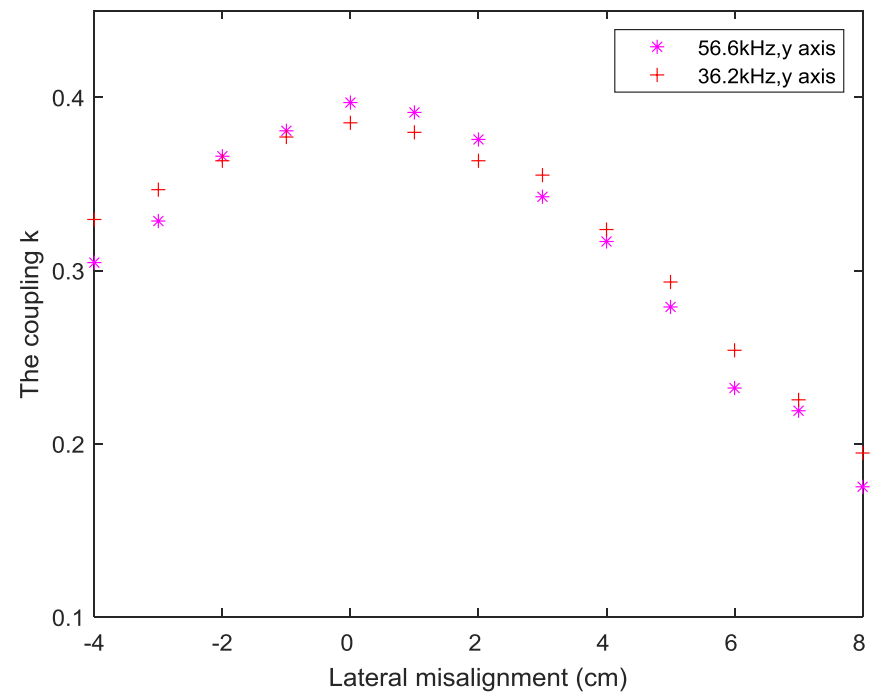

(b)

Fig. 24. Experimental values of the coupling $k$ under misalignment (a) on the $\mathrm{X}$-axis, or (b) on the $\mathrm{Y}$-axis.

\section{CONCLUSIONS}

A wireless system for battery charging adaptive to coil misalignment or range variation based on coupling coefficient estimation is proposed in this study. The system adopts SS basic compensation structure to realize $\mathrm{CC}$ and $\mathrm{CV}$ charging under different equivalent loads. When the coil is under misalignment or range variations, the coupling coefficient is estimated by using the transconductance amplitude equation, and then the input voltage or working frequency are adjusted respectively to achieve $\mathrm{CC}$ or $\mathrm{CV}$ output. However, in the experimental system, we used the power amplifier instead of power electronic converters. The adjustment process in the experiment was done manually rather than by the regulator. The load was used with $4 \Omega$ to $12 \Omega$ resistors, not with real batteries. In the later research, the battery will be used for experiments, power electronics converters will replace the power amplifier, and the DSP regulator will be used to switch the $\mathrm{CC}$ and $\mathrm{CV}$ mode. Our method can combined with studies like [29], [30], [31], [32] and [33].

\section{ACKNOWLEDGMENT}

This work was supported by the National Key R\&D Program of China (2017YFB1302000).

\section{REFERENCES}

[1] I. Mayordomo, T. Drager, P. Spies, J. Bernhard and A. Pflaum. "An Overview of Technical Challenges and Advances of Inductive Wireless Power Transmission". Proceedings of the IEEE, vol. 101, no. 6, pp. 1302-1311, Jun. 2013.

[2] Q. X. Yang, H. Y. Cheng, and G. Z. Xu. "Research Progress in Contactless Power Transfer Technology". Transactions of China Electrotechnical Society, vol. 25, no. 7, pp. 6-13, Jul. 2010 (In Chinese).

[3] S. Sasaki, K. Tanaka, K. Maki. "Microwave Power Transmission Technologies for Solar Power Satellites", Proceedings of the IEEE, vol. 101, no. 6, pp. 1438-1447, Jun. 2013.

[4] S. J. Cheng, X. N. Chen X, J. H. Wang, et al. "Key Technologies and Applications of Wireless Power Transfer". Transactions of China Electrotechnical Society, vol. 30, no. 19, pp. 68-84, Oct. 2015 (In Chinese). 
[5] W. Q. Niu, J. X. Chu, W. Gu, and A.-D. Shen, "Exact Analysis of Frequency Splitting Phenomena of Contactless Power Transfer Systems," IEEE Transactions on Circuits and Systems I: Regular Papers, vol. 60, no. 6, pp. 1670-1677, 2013

[6] H. Feng, R. Tavakoli, O. C. Onar, and Z. Pantic, "Advances in High-Power Wireless Charging Systems: Overview and Design Considerations," IEEE Transactions on Transportation Electrification, vol. 6, no. 3, pp. 886-919, 2020

[7] H. D. Han. "Research on Inductive Power transfer with Constant Current or Voltage Output and IPS Applications", M.S. thesis, Dept. Electron. Eng., Southeast Univ., China, 2016.

[8] L. Cao, Q. Chen, X. Ren, et al. "Review of the Efficient Wireless Power Transfer Technique for Electric Vehicles", Transactions of China Electrotechnical Society, no. 8, pp. 7-19, Aug. 2012 (In Chinese).

[9] W. Niu, W. Gu, and J. Chu, "Experimental investigation of frequency characteristics of underwater wireless power transfer," in 2018 IEEE MTT-S International Wireless Symposium (IWS), 2018

[10] S. Ding, W. Niu, and W. Gu, "Lateral Misalignment Tolerant Wireless Power Transfer with a Tumbler Mechanism", IEEE Access, vol. 7, pp. 125091-125100, Aug. 2019

[11] P. J. Cao. "An IPT System with Nature Constant Voltage and Constant Current Output Features for EV Charging", M.S. thesis, Dept. Electron. Eng., Zhejiang Univ., China, 2019.

[12] M. D. Zhang. "Current situation and development Trend of electric vehicle battery”, Internal Combustion Engine \& Parts, no. 15, pp. 230-231, 2019 (In Chinese).

[13] C. L. Hou, J. Wu, J. P. Li, and M. Zhang. "Research on Battery Charging Technology", Power Supply Technologies and Applications, no. 2, pp. 118-121, Feb. 2004 (In Chinese).

[14] Z. Yin, P. B. Zhang, Y. B. Yang, Y. M. Hu, and Y. Cheng. "Charing Technique of Vehicles Lithium Battery", Internal Combustion Engine \& power plant, no. 3, pp. 1-6, 2010 (In Chinese).

[15] X. Qu, H. Han, S. C. Wong, C. K. Tse, and W. Chen, "Hybrid IPT Topologies with Constant Current or Constant Voltage Output for Battery Charging Applications," IEEE Transactions on Power Electronics, vol. 30, no. 11, pp. 6329-6337, Jan. 2015

[16] H. D. Han, Y. Y. Jing, X. H. Qu. "The IPT Battery Charger with Hybrid Constant-Current and Constant-Voltage Topologies", Journal of Power Supply, vol. 17, no. 2, pp. 132-138, 2019 (In Chinese).

[17] L. Tan, S. Pan, C. Xu, C. Yan, H. Liu, and X. Huang, "Study of constant current-constant voltage output wireless charging system based on compound topologies," Journal of Power Electronics, vol. 17, no. 4, pp. 1109-1116, 2017

[18] Y. Li, Q. Xu, T. Lin, J. Hu, Z. He, and R. Mai, "Analysis and Design of Load-Independent Output Current or Output Voltage of a Three-Coil Wireless Power Transfer System", IEEE Transactions on Transportation Electrification, vol. 4, no. 2, pp. 364-375, Jun. 2018.

[19] Z. C. Huang, S. C. Wong and C. K. Tse. "Design Methodology of a Series-Series Inductive Power Transfer System for Electric Vehicle Battery Charger Application". IEEE Energy Conversion Congress and Exposition, Hong Kong, China, pp. 1778-1782, 2014.

[20] D. H. Tran, V. B. Vu, and W. Choi, "Design of a High-Efficiency Wireless Power Transfer System with Intermediate Coils for the On-Board Chargers of Electric Vehicles", IEEE Transactions on Power Electronics, vol. 33, no. 1, pp. 175-187, Jan. 2018.

[21] V. B. Vu, D. H. Tran, and W. Choi, "Implementation of the Constant Current and Constant Voltage Charge of Inductive Power Transfer Systems with the Double-Sided LCC Compensation Topology for Electric Vehicle Battery Charge Applications", IEEE Transactions on Power Electronics, vol. 33, no. 9, pp. 7398-7410, Sept. 2018

[22] X.H Qu, H.J Chu, Z.C Huang, S.C Wong, et al. "Wide Design Range of Constant Output Current Using Double-Sided LC Compensation Circuits for Inductive-Power-Transfer Applications", IEEE Transactions on Power Electronics, vol. 34, no. 3, pp. 2364-2374, Mar. 2019.

[23] V. Jiwariyavej, T. Imura, and Y. Hori, "Coupling Coefficients Estimation of Wireless Power Transfer System via Magnetic Resonance Coupling Using Information from Either Side of the System", IEEE Journal of Emerging \& Selected Topics in Power Electronics, vol. 3, no. 1, pp. 191-200, Mar. 2015

[24] D. Kobayashi, T. Imura, and Y. Hori, "Real-time coupling coefficient estimation and maximum efficiency control on dynamic wireless power transfer for electric vehicles", in 2015 IEEE PELS Workshop on Emerging Technologies: Wireless Power, 2015.

[25] X. Dai, X. Li, Y. Li, and P. Hu, "Maximum Efficiency Tracking for Wireless Power Transfer Systems with Dynamic Coupling Coefficient
Estimation," IEEE Transactions on Power Electronics, vol. PP, no. 99, pp. 1-1, Jun. 2017.

[26] Y. Liu and H. Feng, "Maximum Efficiency Tracking Control Method for WPT System Based on Dynamic Coupling Coefficient Identification and Impedance Matching Network", IEEE Journal of Emerging and Selected Topics in Power Electronics, vol. PP, no. 99, pp. 1-1, Dec. 2019.

[27] X.M. Fan, L.L. Gao, X.Y. Mo, et al." Overview of Research Status and Application of Wireless Power Transmission Technology", Transactions of China Electrotechnical Society, vol.34, no.7, pp 1353-1380, Apr. 2019.

[28] F. Liu, Y. Yang, D. Jiang, X. Ruan, and X. Chen, "Modeling and Optimization of Magnetically Coupled Resonant Wireless Power Transfer System with Varying Spatial Scales", IEEE Transactions on Power Electronics, vol. 32, no. 4, pp. 3240-3250, Apr. 2017.

[29] Mohamed A. Ebrahim, Reham M. Abdel Fattah, Ebtisam M. Saied, Samir M. Abdel Maksoud, Hisham El Khashab, "Droop Control of an Islanded Microgrid Using Harris hawks optimization Algorithm", Int. J. of Applied Mathematics, Computational Science and Systems Engineering, pp.48-53, Volume 3, 2021.

[30] Maria Isabel Garcia-Planas, Sonia Tarragona, "Analysis of behavior of a simple eigenvalue of singular system", Int. J. of Applied Mathematics, Computational Science and Systems Engineering, pp. 41-47, Volume 3, 2021

[31] Nur Aqilah Othman, Hamzah Ahmad, The Analysis of Covariance Matrix for Kalman Filter based SLAM with Intermittent Measurement, Int. J. of Applied Mathematics, Computational Science and Systems Engineering, pp.66-70, Volume 1, 2019

[32] S.Sivaperumal, V. Sundarapandian, "Hybrid Synchronization of Hyperchaotic Qi Systems via Sliding Mode Control", Int. J. of Applied Mathematics, Computational Science and Systems Engineering, pp.71-75, Volume 1, 2019.

[33] Rashed Bahrekazemi, Alireza Jalilian, "Assessment of Different Compensation Strategies in Hybrid Active Power Filters", Int. J. of Applied Mathematics, Computational Science and Systems Engineering, pp.19-24, Volume 2, 2020.

Wangqiang Niu received the B.E. degree from Xi'an Aerotechnical College, Xi'an, China, in 1998, the M.E. degree from Northwestern Polytechnical University, Xi'an, in 2004, and the Ph.D. degree from Shanghai Jiao Tong University, Shanghai, China, in 2008.

From 2013 to 2014, he was a Visiting Lecturer with McMaster University, Hamilton, ON, Canada. Since 2008, he has been a Lecturer with Shanghai Maritime University, Shanghai, where he has been an Associate Professor, since 2017. His research interests include wireless power transfer and control of marine equipment.

Jiaojiao Liu. received the B.E. degree from the Tongda College of Nanjing University of Posts and Telecommunications, Yangzhou, China, in 2018. She is currently pursuing the M.S. degree with Shanghai Maritime University, Shanghai, China.

Her main research interest includes wireless power transfer technology.

Zaixing Chen received the B.E. degree from Shanghai Dianji University, Shanghai China, in 2002, the M.E.M degree from Queensland University of Technology, Brisbane, Australia, in 2009.

Since 2002, he has been a mechanical designer with Shanghai Zhenhua Heavy Industries Co., Ltd., Shanghai, where he has been a senior engineer, since 2014. His research interests include port machinery and automatic handling equipment.

Wei Gu received the B.E. and Ph.D. degrees from Shanghai Maritime University, Shanghai, China, in 1982 and 2008, respectively.

Since 1982, he has been a Teacher with Shanghai Maritime University, where he has been a Professor, since 1997, and is currently the Director of the Key Laboratory of Transport Industry of Marine Technology and Control Engineering. His research interest includes marine information control technology.

\section{Author Contributions:}

J.L. proposed the WPT charging system method of this paper, carried out the experiment, and wrote the paper.

W.N. guided and revised the paper.

347 W.G. and Z.C. supervised the study. 


\section{Creative Commons Attribution License 4.0} (Attribution 4.0 International, CC BY 4.0)

This article is published under the terms of the Creative Commons Attribution License 4.0

https://creativecommons.org/licenses/by/4.0/deed.en_US 